Long-term mechanical resistance and durability of air lime

mortars with large additions of nanosilica

\author{
A. Duran ${ }^{\text {a }}$ I. Navarro-Blasco ${ }^{\text {a }}$ J.M. Fernández ${ }^{a}$, J.I. Alvarez ${ }^{a^{*}}$
}

${ }^{a}$ MIMED Research Group, Department of Chemistry and Soil Sciences, School of Sciences, University of Navarra. c/ Irunlarrea, 1. 31008 Pamplona, Spain

$\mathbf{N}^{\mathbf{0}}$ of pages: 21

$\mathbf{N}^{\circ}$ of tables: 4

$\mathbf{N}^{\mathbf{0}}$ of figures: 19

Keywords: Colloidal silica, pozzolan, lime mortar, filler effect, C-S-H, climatic ageing

*Corresponding author: Dr. José I. Alvarez Galindo

Dpto. de Química y Edafología

Facultad de Ciencias

Universidad de Navarra

$\mathrm{C} /$ Irunlarrea, 1

31008 Pamplona (Navarra)

Spain

Phone: +34 948425600

Fax: +34 948425740

E-mail: jalvarez@,unav.es, $\underline{\operatorname{mimed} @ \text { unav.es }}$ 


\title{
Long -term mechanical resistance and durability of air lime mortars with large additions of nanosilica
}

\author{
A. Duran ${ }^{\text {a }}$ I. Navarro-Blasco ${ }^{a}$, J.M. Fernández ${ }^{a}$, J.I. Alvarez ${ }^{a^{*}}$ \\ ${ }^{a}$ MIMED Research Group, Department of Chemistry and Soil Sciences, School of Sciences, University of \\ Navarra. c/ Irunlarrea, 1. 31008 Pamplona, Spain
}

\begin{abstract}
The performance of air lime mortars modified by the incorporation of large amounts of nanostructured colloidal silica - nanosilica, NS - $(6,10$ and 20 wt.\% with respect to lime) was the main objective of this work. Fresh mixture properties (water demand, setting time and plastic shrinkage), mechanical strengths up to one year and specimens' durability after accelerated ageing conditions (climatic chamber, freeze-thaw cycles and sulfate attack by $\mathrm{MgSO}_{4}$ corrosion test) were evaluated. NS was seen to have a strong pozzolanic activity in air lime media. Although the addition of NS gave rise to an increase in volume contraction, the superficial cracking caused by the drying shrinkage was reduced. A noticeable increase in the compressive strength values was observed in the NS-bearing mortars owing to the NS filler effect and the C-S-H formation, as proved by SEM examination and MIP analysis. A honeycomb-shaped network of C-S$\mathrm{H}$ phases appeared as the prevailing microstructure in mortars with large NS additions. In the face of accelerated ageing processes, the presence of NS made the mortars more durable, delaying the progress of decay.
\end{abstract}




\section{Introduction}

Nanotechnology can be defined as the science of controlling the properties at nanometer scale which can make revolutionary changes in bulk materials' properties [1]. Potential improvements brought about by using nanoparticles, carbon nanotubes and nanofibers to increase the strength and durability of cementitious composites have been researched $[2,3]$.

Among nanostructured materials, nanosilica (NS) - a suspension of amorphous colloidal silica - has drawn the attention of several researchers because, in cement-based materials, it has shown an outstanding packing ability and pozzolanic activity [4-7]. The small size of NS particles allows them to act as a filler, taking up the voids in the cement composites, thus reducing porosity and enhancing mechanical performance. In addition, the occurrence of a pozzolanic reaction between $\mathrm{NS}$ and $\mathrm{Ca}(\mathrm{OH})_{2}$ present in the cement media yields C-S-H compounds that improve the cohesiveness and strength of the matrix.

Furthermore, the interest of lime-based materials to use to repair works of historical monuments or for rendering mortars can be easily inferred from the growing number of studies dealing with this kind of mortar. Although the role of other pozzolanic additives, e.g. metakaolin, in lime-based mortars, has been widely researched [8-14], few efforts have focused on the performance of lime-based materials modified by the addition of NS [15-16]. In previous works dealing with either lime-based or even cement-based materials, the incorporation of NS was limited to relatively low amounts (around 1-5\% by weight of binding material) $[15,17-19]$. The main objective of the present study is to gain knowledge about the behaviour of air lime mortars modified by the incorporation 
of large amounts of NS (6,10 and 20 wt.\% with respect to lime). Water demand and setting time were evaluated in the fresh mixtures. Additionally, the long-term mechanical resistance was assessed, as well as the durability of the NS-lime mortars in the face of accelerated ageing conditions (climatic chamber, freeze-thaw cycles and corrosion test with magnesium sulfate).

\section{Materials and methods}

\subsection{Materials}

Mortars were prepared taking as binder a dry slaked lime (class CL 90-S according to the European norm [20], supplied by CALINSA). The employed aggregate was a calcitic sand, class AF-T-0/1-C according to norm [21], supplied by Caleras de Liskar (CTG group). The chemical and mineralogical characteristics of the raw materials, and also their grain size distributions, have been reported previously [22]. A colloidal silica suspension supplied by ULMEN Europa S.L. was used as NS. This suspension showed a solid/liquid ratio of 0.28 and $\mathrm{pH}=9.68$. Spherical morphology and size of NS particles were provided by TEM examinations as depicted in Fig. 1 [16].

The selected binder/aggregate ratio was $1: 1$ by volume (1:3 by weight) in accordance with previous studies showing a good performance for this mixture proportion [23]. The water quantity was optimized for the fresh mixtures of the control group in order to obtain a suitable mortar consistency. The workability of the control mortar without NS was considered optimal when the slump in the flow table test was maintained in the range of $175 \pm 5(173 \mathrm{~mm})$, which was reached with a water to lime ratio of 1.12 . This same ratio was kept constant for all the batches of samples, with the aim of assessing the effect of NS addition on the water demand and workability of the fresh mixtures. 
Four different batches of samples were prepared as a function of the amount of NS: PZNS-L0, as a control group with 0 wt.\% NS, PZNS-L6 (6 wt.\% NS with respect to the lime weight), PZNS-L10 (10 wt.\% NS) and PZNS-L20 (20 wt.\% NS).

\subsection{Mortar preparation}

Lime and sand were blended for $5 \mathrm{~min}$ in a BL-8-CA (Lleal S.A.) solid mixer. Afterwards, water - and when necessary, the selected amount of NS suspension - was added and mixed with for $90 \mathrm{~s}$ at low speed in a Proeti ETI 26.0072 mixer. The required amount of fresh mixture was then used for the fresh-state tests, as described below.

For measurement of the properties at hardened state and durability, mortars were molded in prismatic $40 \times 40 \times 160 \mathrm{~mm}$ casts, stored indoors at $60 \% \mathrm{RH}$ and $20^{\circ} \mathrm{C}$, and de-molded 5 days later [24]. Different curing times were set: 7, 28, 91, 182 and 365 days, and three specimens of each mortar were tested at each curing time in order to make the results representative.

Specimens for durability tests were cured for 56 days under the above mentioned curing regime before being subjected to the different assays.

\subsection{Experimental methods}

\subsubsection{Tests on fresh mixtures}

For measuring the fresh state properties, mortars were allowed to settle for $10 \mathrm{~min}$. Afterwards, by means of standardized tests, several properties were measured: 
consistency [25], air content [26] and, as a way of estimation of the setting time, workable life [27].

\subsubsection{Tests on hardened samples}

In hardened samples, at each curing age, the compressive strength experiments were executed on a Proeti ETI 26.0052, the rate of loading being $50 \mathrm{~N} \cdot \mathrm{s}^{-1}$. By means of mercury intrusion porosimetry (MIP), using a Micromeritics AutoPore IV 9500 porosimeter (pressure range between 0.0015 and $207 \mathrm{MPa}$ ), the pore size distributions of the fragments of the samples were obtained. When deemed necessary, samples were manually ground in an agate mortar, so that a complete characterization of the powdered mortars was executed by X-ray diffraction (XRD) (Bruker D8 Advance diffractometer with a $\mathrm{CuK} \alpha 1$ radiation and and a step size of $0.04^{\circ}$ and a time per step of $1 \mathrm{~s}$, from $2^{\circ}$ to $80^{\circ}(2 \theta)$ and Fourier Transform Infrared-Attenuated Total Reflectance (FTIR-ATR) (Nicolet-Avatar 360, resolution of $4 \mathrm{~cm}^{-1}$ ). A simultaneous TG-SDTA 851 Mettler Toledo device allowed us to establish the thermal behaviour of the samples under the following conditions: alumina crucible, $10^{\circ} \mathrm{C} \cdot \mathrm{min}^{-1}$ heating rate, from ambient temperature to $1000^{\circ} \mathrm{C}$, static air atmosphere. The textural examination of the mortars' microstructure was carried out through a Hitachi S-4800 scanning electron microscope (SEM), coupled to an EDS detector. Before SEM-EDS analysis, samples were coated with gold films. Shrinkage assessment was obtained by measuring with a gauge the length variation of a prismatic sample of each one of the mortars at different curing days: $1,3,7,14$ and 28 days. 


\subsubsection{Durability studies}

After 56 days of curing and hardening under ambient laboratory conditions (RH ca. $60 \%$ and temperature around $20^{\circ} \mathrm{C}$ ), prismatic samples of mortars (prepared following the procedure described before) were subjected to different environments:

- Climatic chamber, using a CCI FCH-XENOLAB 1500 chamber with different conditions of temperature, relative humidity, rain and ultraviolet light. The steps corresponding to one of the cycles are set out in Table 1. The duration of each cycle was 48 hours.

- Freeze-thaw cycles, using a CARAVELL 521-102 freezer. The cycles consisted of water immersion of the samples for $24 \mathrm{~h}$ and, straight afterwards, freezing at $10^{\circ} \mathrm{C}$ for $24 \mathrm{~h}$, to assess the frost resistance of the samples.

- Sulfate attack by $\mathrm{MgSO}_{4}$ solution. Samples were completely submerged in an aqueous solution containing $1500 \mathrm{~g} \mathrm{~L}^{-1}$ of $\mathrm{MgSO}_{4}$ (density value in the range $1.292 \pm 0.008 \mathrm{~g} \mathrm{~mL}^{-1}$ ) at $20^{\circ} \mathrm{C}$ for $24 \mathrm{~h}$. After this process, samples were dried in an oven $\left(65^{\circ} \mathrm{C}\right)$ for $24 \mathrm{~h}$ and submerged for $24 \mathrm{~h}$ in water. Finally, to conclude the cycle, the specimens were again dried in the same conditions mentioned above. The cycles were continuously repeated until the total destruction of the specimens.

To assess the endurance of the samples after the ageing cycles, two parameters were considered: (i) a qualitative evaluation based on visual appearance and (ii) compressive strength tests when the integrity of the samples allowed them. The qualitative evaluation was visually determined, using a previously reported criterion [28], which attributes:

- degree 0 of alteration for those samples with no evidence of decay;

- degree 1 for samples showing a slight degree of deterioration (some thin, short, shallow cracks on the surface of the specimens); 
- degree 2 for altered samples, showing several deeper cracks;

- degree 3 for heavily altered specimens presenting deep cracks and a certain degree of swelling;

- degree 4 for samples with severe decay, large, deep cracks, partial weight loss and large swelling;

- degree 5 for completely destroyed samples, with only some parts remaining.

This examination was performed when each cycle was concluded in the case of freezethaw and $\mathrm{MgSO}_{4}$ corrosion resistance experiments, and after 7, 14 and 28 cycles for tests in the climatic chamber.

Compressive strength experiments were performed after 7, 14 and 28 cycles in all the samples exposed to the aforementioned environments, on condition that the samples were not totally decayed.

\section{Results and discussion}

\subsection{Assessment of the fresh- and hardened-state properties.}

Growing amounts of NS increased the water demand of the lime mortars, as evidenced by the fluidity reduction (slump reduction in Table 2), reaching $27 \%$ of flowability reduction with 20 wt.\% of NS (sample PZNS-L20). This fact was a consequence of the packing ability of the NS: as NS fills in the voids and increases the density, the workability of the sample undergoes a reduction. In addition, the formation of C-S-H gel also increases the water consumption, so that more water would be necessary to achieve enough workability. 
The presence of C-S-H was evidenced thanks to the studies by FT-IR as well as the SEM-EDX examinations that will be described below. The reaction between $\mathrm{CH}$ particles and the reactive $\mathrm{SiO}_{2}$ belonging to NS yielded calcium silicate hydrates (C-SH) with tobermorite-like structures [29]. This reaction involved a polymerization of the silica of the nanoparticles, which underwent an increasing degree of connectivity. The broad IR band that appears in the spectra at around $1100 \mathrm{~cm}^{-1}$ (Fig. 2) was attributed to asymmetric stretching frequency of Si-O-Si. A shift of the former band to higher wavenumbers was observed in our samples: from 1083 to $1090 \mathrm{~cm}^{-1}$ when the NS content increased from 6 to $20 \%$, in good agreement with previous publications [15].

Both the shift of the Si-O stretching vibration to higher frequencies and the broadening of this band have been described as being fingerprint evidence for the degree of polymerization with the formation of $\mathrm{C}-\mathrm{S}-\mathrm{H}$ phase as a result of cement hydration [30,31]. The results obtained by Björnstrom et al. [31] confirmed that Si-O vibrational frequencies certainly increased with the higher connectivity of the silicate network.

During the fresh-state (plastic period), the drying of the mortars can lead to shrinkage of the initial volume. If the mortar is not able to deform at a rate that is enough to diminish the stress, then the cracking phenomenon can take place. This drying process is the consequence of an internal relative humidity reduction, giving rise to a self-desiccation of the mortar and subsequent volume shrinkage. In addition, chemical shrinkage is also possible in cement mortars due to the reduction in volume as a result of the hydration of anhydrous compounds of the cement. 
In the mortars assayed, the presence of NS raised the shrinkage as compared to plain lime mortar (sample PZNS-L0) (Fig. 3), especially taking into account that the water consumed by hydration of C-S-H had also an influence on shrinkage. These results were in line with those published elsewhere, in which the incorporation of a pozzolanic addition (silica fume) into air lime mortars caused a shrinkage increase [32]. It can be assumed that the total shrinkage was the result of a combination of two contributions: drying shrinkage and chemical shrinkage due to the hydration and subsequent formation of C-S-H phases. In addition, in NS-doped mortars, the filler action of the NS in the meso and microporous range [16] improved the packing of the sample, thus causing a volume contraction. These facts would explain the lowest shrinkage value observed for the plain air lime mortar (NS-free mortar), which did not have the contribution of either the chemical shrinkage or the filler effect of NS. However, there was no clear relationship between the dosage of the pozzolanic additive and the shrinkage.

Finally, the plastic mortars were spread over an absorbent brick in order to assess the effects of the shrinkage visually in terms of superficial cracking (Fig. 4). The thickness of the mortar layer applied was around $1 \mathrm{~cm}$. It can be observed that, although the shrinkage values were higher for NS-bearing mortars, the presence of NS diminished the cracking over the surface of the mortar. In this sense, it is reasonable to argue that the addition of NS, while increasing the chemical shrinkage because of the formation of C-S-H compounds, caused a reduction in the contribution of the drying shrinkage, given that the hydration of calcium silicates consumed free water, the main factor responsible for the drying shrinkage and subsequent superficial cracking. It should be noticed that some previous works reported very limited cracking in lime mortars [33] whereas some other authors found significant cracking in this kind of mortars [22,34,35]. This slight 
controversy could be related to the the fact that the cracks formation depends on diverse factors, such as the mixing water, the water/lime ratio, the curing regime, the presence of pozzolanic addition, the use of organic admixtures or the water sorption capability of the brick. Changes in some of these parameters could lead to variable results in terms of superficial cracking. However, in the current work, comparatively, NS-bearing mortars showed better performance than plain mortars.

The air content showed negligible variations upon the addition of NS (Table 2). However, the setting time of the mortars (as measured by the workable life test [27]) underwent a delay as the percentage of NS increased up to $10 \mathrm{wt} \% \mathrm{NS}$, with a maximum at a loading of 6 wt.\% NS (sample PZNS-L6) (Table 2). This was an unexpected result, because the progress of pozzolanic reaction should give rise to a setting time reduction $[5,7,15]$. However, it must be considered that the water availability was limited for NS-bearing mortars, so that, in a very early stage, the formation of C-S-H could be partially delayed. The incorporation of $20 \mathrm{wt} \%$ of NS slightly shortened the workable life with respect to the control group. Among others, this fact could be related to the densification of the matrix due to the large amount of NS. Further studies will be necessary to elucidate the exact influence of NS on the setting time of these mortars.

One of the most well-known disadvantages of lime mortars is their long setting times, which make their application difficult $[21,36,37]$. The addition of large amounts of NS did not overcome this problem, although the incorporation of $20 \mathrm{wt} . \%$ NS showed a setting time very similar to that observed for plain lime mortars. 
A noticeable increase in the compressive strength values could be observed in the NSbearing mortars even at early curing times. In this form, compressive strength was four times as much as the control value (1.3 MPa for PZNS-L0) at only 28 curing days when the highest amount of NS (20 wt.\%) was added (5.2 MPa for PZNS-L20). The progressive increase of NS content shifted the values of compressive strength towards higher values (Fig. 5). After 182 curing days, compressive strength increased from 3.5 MPa for NS-free sample to $5.4 \mathrm{MPa}$ for sample with 20\% wt. NS (increment by 54\%). This behaviour could mainly be ascribed to two governing factors. First, the pozzolanic reaction that took place between $\mathrm{CH}$ particles and reactive silica of the NS, forming $\mathrm{C}$ $\mathrm{S}-\mathrm{H}$ phases, responsible for the observed mechanical strength improvement [5]. Secondly, the noticeable filling effect due to the blockage of pores executed by NS, thus resulting in a reduction of the mean pore size (Figure 7). The extent of the carbonation confirmed the occurrence of the pozzolanic reaction between $\mathrm{CH}$ and NS: results by DTA/TG showed that lower percentages of carbonation $\left(\mathrm{CaCO}_{3}\right.$ formation) were provided when NS percentage increased, owing to the faster consumption of the $\mathrm{CH}$ during the pozzolanic reaction (Table 3 ).

This pozzolanic reaction was also responsible for the rapid growth in strength. The 7day strengths were $50.0 \%, 54.8 \%$ and $65.0 \%$ of the 28 -day values for samples PZNSL6, PZNS-L10 and PZNS-L20, respectively. These figures are progressively similar to those of the cement-based concretes, in which 7-day strength is typically 65 to $75 \%$ of the value at 28 days [38]. However, the plain lime mortar showed 7-day strength $(0.4$ $\mathrm{MPa})$ that was only $30.8 \%$ of the 28 -day value $(1.3 \mathrm{MPa})$, so that the presence of NS improved the strength growth rate. As for other pozzolanic additions, such as metakaolin, literature reported extensive data on the behaviour of lime-MK mortars. For 
instance, Gameiro et al. showed, in humid curing conditions, the pozzolanic interaction as the dominant reaction at early curing times [12]. Slavid et al. - under not exactly the same conditions - reported that this reaction is characterized by relatively slow progress [38]. In the latter work, for instance, a metakaolin-lime mortar showed a 7-day strength of just $36 \%$ of the 28 -day value [38]. In other studies, strongly influenced by the different experimental conditions and raw materials, the extent of the pozzolanic reaction, and consequently of the compressive strengths achieved, was relatively low $[13,39]$.

In the present study, NS promoted both the rate and intensity of the pozzolanic reaction. The evolution of the most intense diffraction signal of the calcium hydroxide over time allowed us to estimate the consumption of the portlandite and, therefore, the extent and rate of the pozzolanic reaction. Plain lime mortar (sample PZNS-L0) showed a progressive decrease in this peak owing to the carbonation, whereas the presence of NS increased the rate of $\mathrm{CH}$ consumption even at early curing times (7 days) (Fig. 6). After 182 curing days, there was still a slight amount of uncarbonated portlandite in plain lime mortar, in good agreement with previous work [40,41], but in NS-bearing samples the remaining $\mathrm{CH}$ was almost negligible, evidencing an almost complete pozzolanic reaction.

Thermogravimetric analysis also confirmed these results. Table 4 shows the $\mathrm{Ca}(\mathrm{OH})_{2}$ percentages calculated (weight loss at ca. $450^{\circ} \mathrm{C}$, corresponding to the portlandite dehydroxylation) at different curing times. After 7 curing days, the consumption of the portlandite was stronger in samples with NS than in plain lime mortar. As a general 
trend, the rate of $\mathrm{Ca}(\mathrm{OH})_{2}$ reduction was higher for NS-bearing mortars up to 28 curing days, proving that most of the pozzolanic reaction took place in early curing periods.

The filler effect provoked by NS addition was studied by MIP. The progressive increase in NS (from 0 to $20 \mathrm{wt} . \%$ ) shifted the mean pore size diameter (PSD) towards lower diameters: around $0.8 \mu \mathrm{m}$ for PZNS-L0, $0.55 \mu \mathrm{m}$ for PZNS-L6, and $0.43 \mu \mathrm{m}$ for PZNSL10. The most dramatic change in the PSD was observed for the samples with $20 \%$ NS (PZNS-L20), in which a bimodal distribution, with maxima at 0.43 and between 0.1 and $0.05 \mu \mathrm{m}$, was seen. In the latter samples, a high percentage of pores with diameters lower than $0.2 \mu \mathrm{m}$ was detected (Fig. 7). This behaviour took place at all the curing times, as can be observed in Fig. 7 with PSD after 7, 28, 91, 182 and 365 curing days. The reduction in the mean pore size diameter suggests a densification of the matrix caused by the nanofiller effect of the NS. Also the formation of C-S-H could contribute to this pore size reduction, which correlates with the increase in compressive strength values. The increase in the population of pores of small size was the expected consequence of the inclusion of a nanostructured material, which after filling voids, creates small pores between the particles.

The textural examination by SEM of the samples showed that the overall morphology of C-S-H can actually vary from the common fibrous type to irregular clusters and areas forming a reticular network. In any case, C-S-H compounds, with honeycomb-shaped, flaky structures, are clearly observed in the micrographs of the samples after 91 curing days (Fig. 8). The appearance of these morphologies (also confirmed by EDAX analysis) and their prevalence was a clear evidence of the large extent of the pozzolanic reaction, confirming previous data of XRD and TG studies [42,43]. In the control group 
(NS-free sample) irregular agglomerations of scalenohedral calcite crystals could be observed together with a few hexagonal plate-like crystals of portlandite not yet carbonated.

As seen in the micrographs of the samples after 182 curing days (Fig. 9), in good agreement with the MIP results, the progressive addition of NS resulted in a denser matrix, with an interlinked structure, responsible for the better mechanical performance of these mortars. The increase in curing time (and, therefore, the carbonation degree) did not substantially modify the microstructure of the NS-bearing mortars, so that the incorporation of NS in these mortars was more critical for the obtaining of a specific microstructure than the carbonation of portlandite.

\subsection{Durability studies}

Among the different ageing conditions, the climatic chamber exposure was the least detrimental condition for the assayed samples. As a general trend, all the prepared mortars withstood the first cycles of this environment. For example, after 7 cycles, there was no clear visual evidence of decay, with degree 0 for all the samples. Nevertheless, compressive strength values (Fig. 10) showed a reduction - but still measurable after 7 cycles - as compared to those measured after normal curing conditions.

The control group samples subjected to frost resistance test (F-T cycles) underwent serious decay, in such a way that they were totally destroyed after just one cycle (Fig. 11). This deleterious effect of the F-T cycles in plain lime mortars is in good agreement with data reported elsewhere [44]. The incorporation of NS outstandingly enhanced the durability of the mortars in the face of these F-T cycles. It can be seen that samples with 
20 wt.\% NS can endure up to $17 \mathrm{~F}-\mathrm{T}$ cycles. Both the porosity and pore size reduction when NS was added could explain these results because a reduced porosity hindered the absorption of liquid water, preventing its later freezing and expansion damage. In Fig. 12 and Fig. 13, pictures of the samples after being subjected to, respectively, 5 and 10 F-T cycles, show that the presence of NS gave rise to more durable mortars. In addition, specimens show evidence of the swelling and subsequent appearance of a fissure in the inner part of the specimen as the main visual consequence of the alteration.

Compressive strength resistances (after 7 and 14 F-T cycles) were found to remain significant just for samples with the largest additions of NS (10 and 20 wt.\%) (Fig. 14).

The assessment of the resistance to sulfate attack of aggressive $\mathrm{MgSO}_{4}$ solution was also studied. The qualitative estimation of the degree of decay is reported in Fig. 15. It can be deduced that samples were sensitive to this aggressive environment, since after 10 cycles all samples achieved a degree of 5 (complete decay). The presence of NS, as in the case of F-T cycles, favoured the resistance of the mortars against the sulfate attack. The larger the amount of NS, the higher the number of cycles that a specimen tolerated.

Fig. 16 shows the pictures of the specimens of all the assayed mortars after 4 cycles of exposure, while Fig. 17 shows, as an example, the evolution of the PZNS-L6 samples over the different cycles, depicting the severe decay that sulfate attack caused in the mortars. The formation of white crusts and efflorescences, together with the dissolution and loss of solid material (disintegration of the sample), suggests that the formation of calcium sulfate and its leaching was the main mechanism explaining the alteration of 
the mortars under this aggressive environment. The formation of calcium sulfate and brucite, $\mathrm{Mg}(\mathrm{OH})_{2}$, is the consequence of the reaction between calcium hydroxide and magnesium sulfate [45]. The deterioration pattern started in the corners and was extended by cracking along the edges of the prismatic specimens. The spalling of the superficial part of the specimens also took place, in line with previous findings about the magnesium sulfate attack to cement-based materials [45]. In addition to that, the formation of thaumasite $\left(\mathrm{CaSiO}_{3} \cdot \mathrm{CaCO}_{3} \cdot \mathrm{CaSO}_{4} \cdot 15 \mathrm{H}_{2} \mathrm{O}\right)$ has been reported as another deterioration mechanism of cementitious materials under sulfate attack, on condition that sulfate and carbonate ions, as well as calcium silicates, are available [46]. Preferential formation of thaumasite requires excess of humidity and low temperatures. The source of silicon during thaumasite formation is the dissolution and subsequent decomposition of C-S-H, giving as a result of the sulfate attack a mushy material with a sharp loss of cohesiveness [47]. The analysis by XRD of the degradation products obtained after exposure of the samples to sulfate attack proved that the two mechanisms were responsible for the damage of the mortars. In Fig. 18 can be observed, as an example, the identification of calcium sulfate and brucite, as well as thaumasite, in the surface material degradation of the PZNS-L6 sample, after several cycles of exposure to magnesium sulfate attack.

The pozzolanic reaction that took place in mortars with NS reduced the amount of $\mathrm{CH}$, so that the amount of calcium sulfate formed during the sulfate attack diminished, giving rise to higher resistance $[45,46,48]$. In cement mortars, the addition of pozzolanic admixtures that cause a refinement on the pore structure has been reported to improve the resistance of these mortars in the face of sulfate attack [45]. In the present study, the addition of NS enhanced the resistance, delaying the sulfate attack, as proved in Fig. 15 
(alteration degrees) and in Fig. 19, by the compressive strength results of the tested samples.

\section{Conclusions}

The consequences of the incorporation of large amounts of nanosilica, as a pozzolanic admixture, into air lime mortars have been investigated. The presence of NS increased the water demand and reduced the flowability of the fresh mixtures. In lime mortars, NS, even in large amounts, has been proved to have an outstanding pozzolanic activity. Although the presence of NS caused a volume contraction, the superficial cracking was reduced owing to the reduction of the drying shrinkage.

Remarkable compressive strength increments were found for samples with large percentages of NS. In long-term tests (182 curing days), sample with 20 wt.\% NS showed an increase of $54 \%$ with respect to the control sample. The pore size distributions showed a clear filler effect of NS, which yielded a denser matrix in good agreement with the enhanced mechanical resistance.

Textural examination by SEM confirmed the intense pozzolanic reaction and allowed us to establish the honeycomb shape as the predominant microstructure in mortars with large additions of NS. It was found that the incorporation of NS was more critical for the final characteristics of these mortars than the carbonation progress.

Durability studies were also carried out on the mortars. Climatic chamber and freezethaw cycles caused a severe decay owing to the mechanical effect of the F-T process. The sulfate attack was even more detrimental for the mortars, as a consequence of the 
concurrence of two deterioration processes: (i) the chemical reaction between calcium hydroxide and magnesium sulfate forming soluble calcium sulphate, and (ii) the thaumasite formation that caused the degradation of the C-S-H compounds. These two damage mechanisms eventually gave rise to disintegration of the sample. In the three accelerated ageing processes tested, the presence of large amounts of NS improved the durability of the air lime mortars, delaying the decay evolution.

\section{Acknowledgements}

The authors want to thank CTH Navarra and Calinsa S.A. Navarra for the material supplied. They also gratefully acknowledge Dr. M.C. Jiménez de Haro (ICMS) for her assistance in the SEM analysis. This work was funded by Fundación Universitaria de Navarra under grant FUNA2013-15108402.

\section{References}

[1] Singh LP, Karade SR, Bhattacharyya SK, Yousuf MM, Ahalawat S. Beneficial role of nanosilica in cement based materials - A review. Constr Build Mater 2013; 47: 106977.

[2] Zhu W, Bartos PJM, Porro A. Application of nanotechnology in construction. Summary of a state-of-the-art report. Mater Struct 2004; 37: 649-58.

[3] Pacheco-Torgal F, Jalali S. Nanotechnology: Advantages and drawbacks in the field of construction and building materials. Constr Build Mater 2011; 25 (2): 582-90.

[4] Shih J-Y, Chang T-P, Hsiao T-C. Effect of nanosilica on characterization of Portland cement composite. Mater Sci Eng. A-Struct 2006; 424 (1-2): 266-74.

[5] Quercia G, Hüsken G, Brouwers HJH. Water demand of amorphous nano silica and its impact on the workability of cement paste. Cem Concr Res 2012; 42 (2): 344-57.

[6] Haruehansapong S, Pulngern T, Chucheepsakul S. Effect of the particle size of nanosilica on the compressive strength and the optimum replacement content of cement mortar containing nano-SiO 2 . Constr Build Mater 2014; 50: 471-7. 
[7] Zhang M-H, Islam J. Use of nano-silica to reduce setting time and increase early strength of concretes with high volumes of fly ash or slag. Constr Build Mater 2012; 29: 573-80.

[8] Sepulcre-Aguilar A, Hernández-Olivares F. Assessment of phase formation in limebased mortars with added metakaolin, Portland cement and sepiolite, for grouting of historic masonry. Cem Concr Res 2010; 40 (1): 66-76.

[9] Fortes-Revilla C, Martínez-Ramírez S, Blanco-Varela MT. Modelling of slaked lime-metakaolin mortar engineering characteristics in terms of process variables. Cem Concr Compos 2006; 28 (5): 458-67.

[10] Aggelakopoulou E, Bakolas A, Moropoulou A. Properties of lime-metakolin mortars for the restoration of historic masonries. Appl Clay Sci 2011; 53 (1): 15-9.

[11] Arizzi A, Cultrone G. Aerial lime-based mortars blended with a pozzolanic additive and different admixtures: A mineralogical, textural and physical-mechanical study. Constr Build Mater 2012; 31: 135-43.

[12] Gameiro A, Santos Silva A, Faria P, Grilo J, Branco T, Veiga R, Velosa A. Physical and chemical assessment of lime-metakaolin mortars: Influence of binder:aggregate ratio. Cem Concr Comp 2014; 45: 264-71.

[13] Andrejkovičová S, Velosa A, Gameiro A, Ferraz E, Rocha F. Palygorskite as an admixture to air lime-metakaolin mortars for restoration purposes. Appl Clay Sci 2013; 83-84: 368-74.

[14] Vejmelková E, Keppert M, Keršner Z, Rovnaníková P, Černý R. Mechanical, fracture-mechanical, hydric, thermal, and durability properties of lime-metakaolin plasters for renovation of historical buildings. Constr Build Mater 2012; 31: 22-8.

[15] Fernández JM, Duran A, Navarro-Blasco I, Lanas J, Sirera R, Alvarez JI. Influence of nanosilica and a polycarboxylate ether superplasticizer on the performance of lime mortars. Cem Concr Res 2013; 43: 12-24.

[16] Alvarez JI, Fernández JM, Navarro-Blasco I, Duran A, Sirera R. Microstructural consequences of nanosilica addition on aerial lime binding materials: Influence of different drying conditions. Mater Charact 2013; 80: 36-49.

[17] Kim JJ, Rahman MK, Al-Majed AA, Al-Zahrani MM, Taha MMR. Nanosilica effects on composition and silicate polymerization in hardened cement paste cured under high temperature and pressure. Cem Concr Compos 2013; 43: 78-85.

[18] Berra M, Carassiti F, Mangialardi T, Paolini AE, Sebastiani M. Effects of nanosilica addition on workability and compressive strength of Portland cement pastes. Constr Build Mater 2012; 35: 666-75.

[19] Kontoleontos F, Tsakiridis PE, Marinos A, Kaloidas V, Katsioti M. Influence of colloidal nanosilica on ultrafine cement hydration: Physicochemical and microstructural characterization. Constr Build Mater 2012; 35: 347-60. 
[20] CEN EN 459-1, Building Lime, Part 1: definition, specification and conformity criteria, 2010.

[21] CEN EN 13139, 2003/AC. Aggregates for mortars; 2004.

[22] Izaguirre A, Lanas J, Alvarez JI. Effect of water-repellent admixtures on the behaviour of aerial lime-based mortars. Cem Concr Res 2009; 39 (11): 1095-104.

[23] Lanas J, Alvarez-Galindo JI. Masonry repair lime-based mortars: factors affecting the mechanical behavior. Cem Concr Res 2003; 33 (11): 1867-76.

[24] CEN EN 1015-11, Methods of Test for Mortar for Masonry, Part 11: Determination of flexural and compressive strength of hardened mortar, 2000.

[25] CEN EN 1015-3, Methods of Test for Mortar for Masonry, Part 3: Determination of consistence of fresh mortar (by flow table), 2000.

[26] CEN EN 1015-7: Methods of test for mortars for masonry, Part 7: Determination of air content of fresh mortar, 1999.

[27] CEN EN 1015-9, Methods of test for mortar for masonry, Part 9: Determination of workable life and correction time of fresh mortar, 2000.

[28] Lanas J, Sirera R, Alvarez JI. Study of the mechanical behavior of masonry repair lime-based mortars cured and exposed under different conditions. Cem Concr Res 2006; 36 (5): 961-70.

[29] Sáez del Bosque IF, Martínez-Ramírez S, Blanco-Varela MT. FTIR study of the effect of temperature and nanosilica on the nano structure of $\mathrm{C}-\mathrm{S}-\mathrm{H}$ gel formed by hydrating tricalcium silicate. Constr Build Mater 2014; 52: 314-23.

[30] Mollah MYA, Yu W, Schennach R, Cocke DL. A Fourier transform infrared spectroscopic investigation of the early hydration of Portland cement and the influence of sodium lignosulfonate. Cem Concr Res 2000; 30 (2): 267-73.

[31] Björnström J, Martinelli A, Matic A, Börjesson L, Panas I. Accelerating effects of colloidal nano-silica for beneficial calcium-silicate-hydrate formation in cement. Chem Phys Lett 2004; 392 (1-3): 242-8.

[32] Sánchez JA, Barrios J, Barrios A, Arellano Agudo AR. The shrinkage in lime mortars. Mater Construcc 1997; 47 (245): 17-28.

[33] Silva, J, Brito, J, Veiga, MR. Incorporation of fine ceramics in mortars. Constr Build Mater 2009; 23: 556-564.

[34] Izaguirre A, Lanas J, Álvarez JI. Behaviour of a starch as a viscosity modifier for aerial lime-based mortars. Carbohydr Polym 2010; 80(1): 222-228. 
[35] Izaguirre A, Lanas J, Alvarez JI. Effect of a polypropylene fibre on the behaviour of aerial lime-based mortars. Constr Build Mater 2011; 25(2): 992-1000.

[36] Rodriguez-Navarro C, Hansen E, Ginell WS. Calcium hydroxide crystal evolution upon aging of lime putty. J Am Ceram Soc 1998; 81 (11): 3032-34.

[37] Arandigoyen M, Alvarez JI. Blended pastes of cement of cement and lime: pore structure and capillary porosity. Appl Surf Sci 2006; 252 (23): 8077-85.

[38] Slavid I, Thomson ML, Wathne J, Weiss NR. Development and evaluation of a lime-metakaolin grout, $3^{\text {rd }}$ Historic Mortars Conference, Ed. J.J. Hughes, University of the West of Scotland, Glasgow 2013, pp. 106.

[39] Cardoso D, Gameiro A, Santos Silva A, Faria P, Vieira R, Veiga R, Velosa A. Influence of curing conditions in air lime-metakaolin blended mortars - A mineralogical and mechanical study. Ed. J.J. Hughes, University of the West of Scotland, Glasgow 2013, pp. 89.

[40] Arandigoyen M, Álvarez JI. Carbonation process in lime pastes with different water/binder ratio. Mater Construcc 2006; 56 (281): 5-18.

[41] Lanas J, Pérez Bernal JL, Bello MA, Alvarez JI. Mechanical properties of masonry repair dolomitic lime-based mortars. Cem Concr Res 2006; 36(5): 951-60.

[42] Lin RB, Shih SM, Liu CF. Characteristics and reactivities of $\mathrm{Ca}(\mathrm{OH})_{2} /$ silica fume sorbents for low-temperature flue gas desulfurization. Chem Eng Sci 2003; 58 (16): 3659-68.

[43] Baltakys K, Jauberthie R, Siauciunas R, Kamisnskas R. Influence of modification of $\mathrm{SiO}_{2}$ on the formation of calcium silicate hydrate. Materials Science-Poland 2007; 25 (3): 663-670.

[44] Izaguirre A, Lanas J, Alvarez JI. Ageing of lime mortars with admixtures: Durability and strength assessment. Cem. Concr. Res. 2010; 40 (7): 1081-95.

[45] Skaropoulou A, Tsivilis S, Kakali G, Sharp JH, Swamy RN. Long term behavior of Portland limestone cement mortars exposed to magnesium sulfate attack. Cem Concr Compos 2009; 31 (9): 628-36.

[46] Skaropoulou A, Tsivilis S, Kakali G, Sharp JH, Swamy RN. Thaumasite form of sulfate attack in limestone cement mortars: A study on long term efficiency of mineral admixtures. Constr Build Mater 2009; 23 (6): 2338-45.

[47] Köhler S, Heinz D, Urbonas L. Effect of ettringite on thaumasite formation. Cem Concr Res 2006; 36 (4): 697-706.

[48] Zelić J, Krstulović R, Tkalčec E, Krolo P. Durability of the hydrated limestonesilica fume Portland cement mortars under sulphate attack. Cem Concr Res 1999; 29 (6): 819-26. 
Table 1. Steps of the ageing cycle in the climatic chamber.

\begin{tabular}{cccccc}
\hline Step & T ( $\left.{ }^{\circ} \boldsymbol{C}\right)$ & RH (\%) & Rain & UV light & Time (h) \\
\hline 1 & 35 & 30 & - & - & 12 \\
2 & 45 & 20 & - & $\checkmark$ & 12 \\
3 & 12 & 95 & $\checkmark$ & - & 1 \\
4 & 12 & 95 & - & - & 4.5 \\
5 & 12 & 95 & $\checkmark$ & - & 1 \\
6 & 12 & 95 & - & - & 4.5 \\
7 & 12 & 95 & $\checkmark$ & - & 1 \\
8 & -5 & 0 & - & - & 12 \\
\hline
\end{tabular}

Table 2. Fresh state properties.

\begin{tabular}{cccc}
\hline Sample & $\begin{array}{c}\text { Flowability } \\
\text { (flow measured by slump in } \mathrm{mm})\end{array}$ & $\begin{array}{c}\text { Air content } \\
(\%)\end{array}$ & $\begin{array}{c}\text { Setting time } \\
(\mathrm{min})\end{array}$ \\
\hline PZNS-LO & 173 & 3.2 & 215 \\
PZNS-L6 & 167 & 3.4 & 980 \\
PZNS-L10 & 146 & 3.2 & 494 \\
PZNS-L20 & 126 & 3.4 & 208 \\
\hline
\end{tabular}

Table 3. Percentage of $\mathrm{CaCO}_{3}$ as calculated from TG results (samples after 182 curing days).

\begin{tabular}{cc}
\hline Sample & $\begin{array}{c}\mathrm{CaCO}_{3} \\
(\%)\end{array}$ \\
\hline PZNS-LO & 91.60 \\
PZNS-L6 & 90.54 \\
PZNS-L10 & 87.50 \\
PZNS-L20 & 81.95 \\
\hline
\end{tabular}

Table 4. Percentages of $\mathrm{Ca}(\mathrm{OH})_{2}$ calculated from $\mathrm{TG}$ analysis.

\begin{tabular}{ccccc}
\hline Curing days & PZNS-L0 & PZNS-L6 & PZNS-L10 & PZNS-L20 \\
\hline 7 & 12.29 & 10.86 & 6.87 & 4.40 \\
$\mathbf{2 8}$ & 7.11 & 5.39 & 4.28 & 0.95 \\
$\mathbf{1 8 2}$ & 4.07 & 2.38 & 1.48 & 0.66 \\
\hline
\end{tabular}




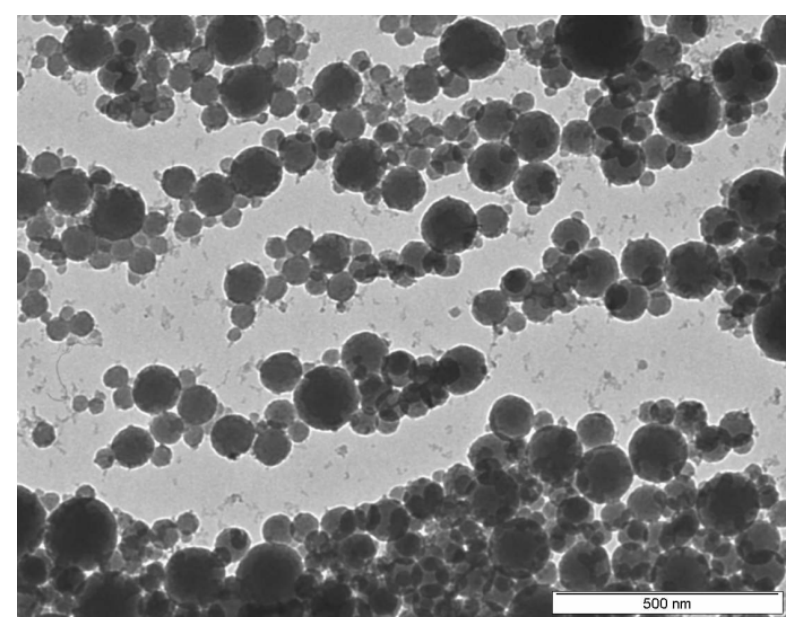

Figure 1. TEM examination of the colloidal suspension of NS.

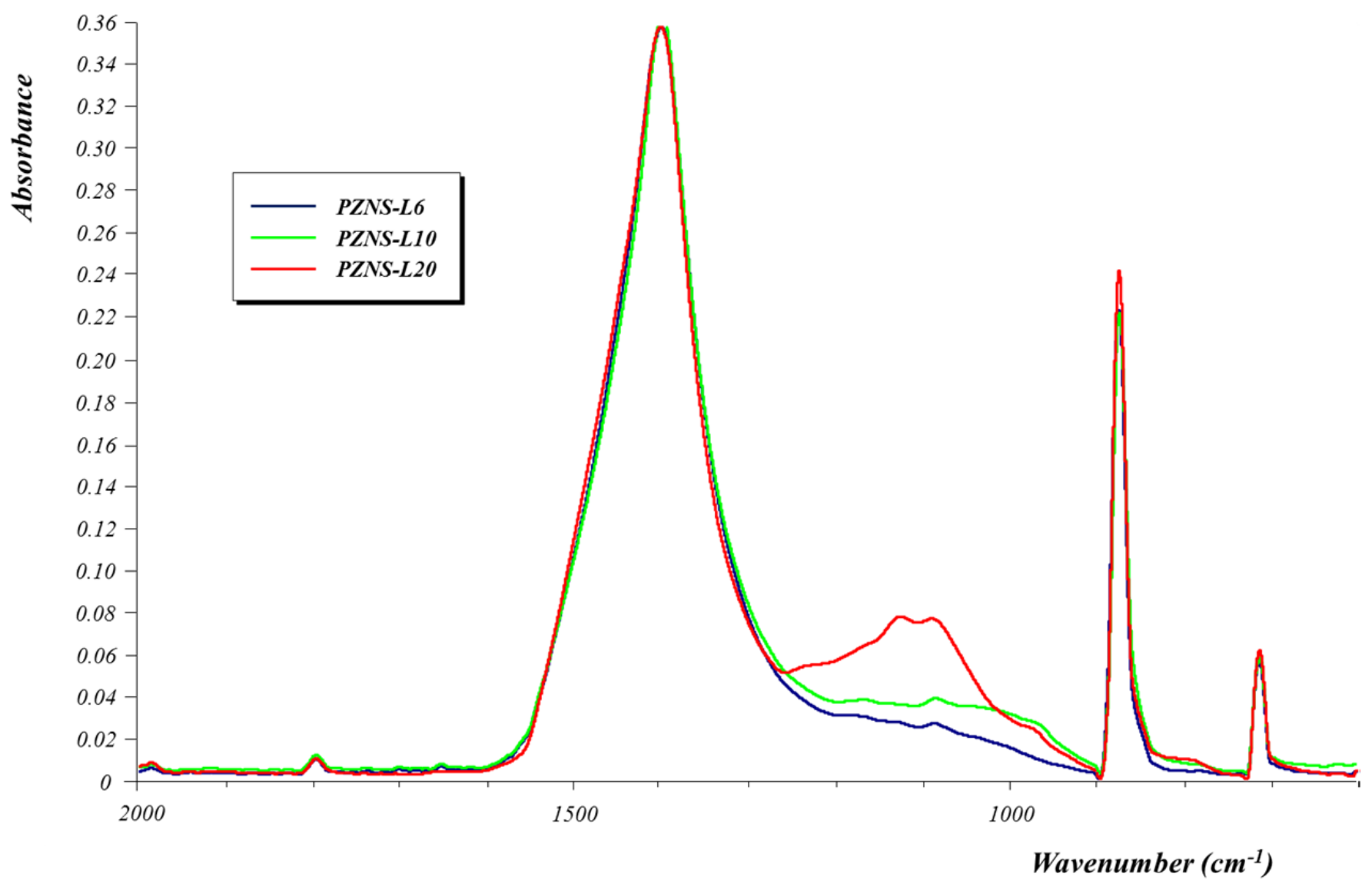

Figure 2. FTIR spectra of the samples with NS. 


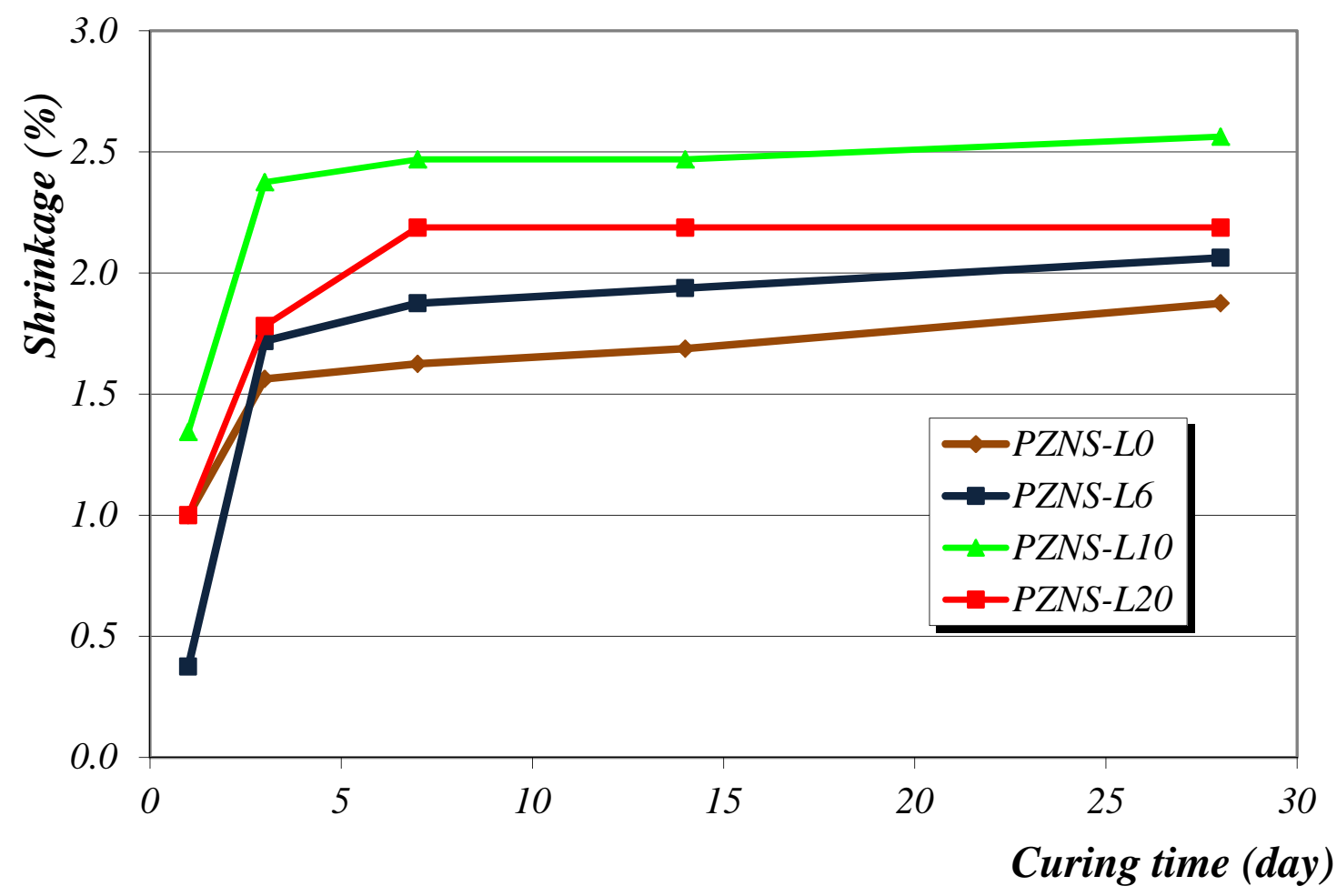

Figure 3. Shrinkage of the samples vs. curing time.
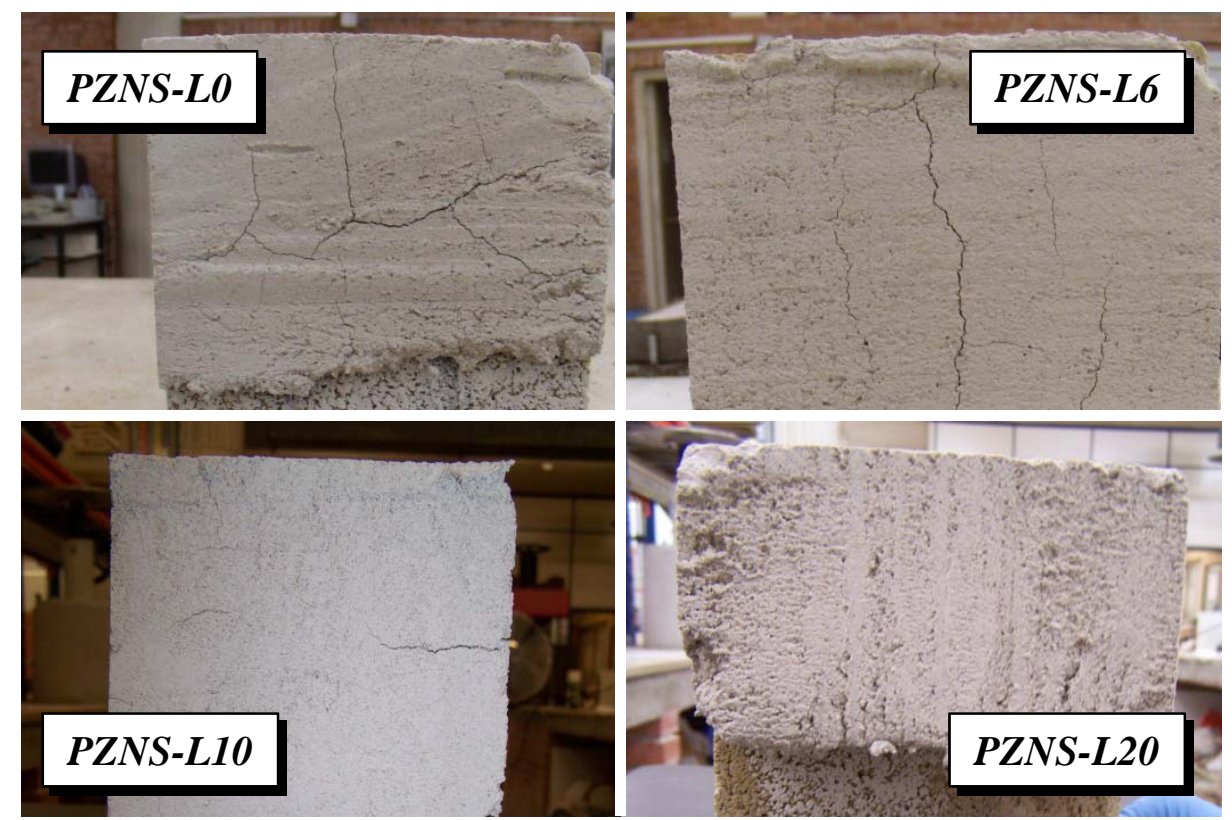

Figure 4. Visual examination of a layer of the mortars spread over the surface of an absorbent material: samples from 0 to $20 \mathrm{wt} \%$ NS (PZNS-L0, PZNS-L6, PZNS-L10 and PZNS-L20). 


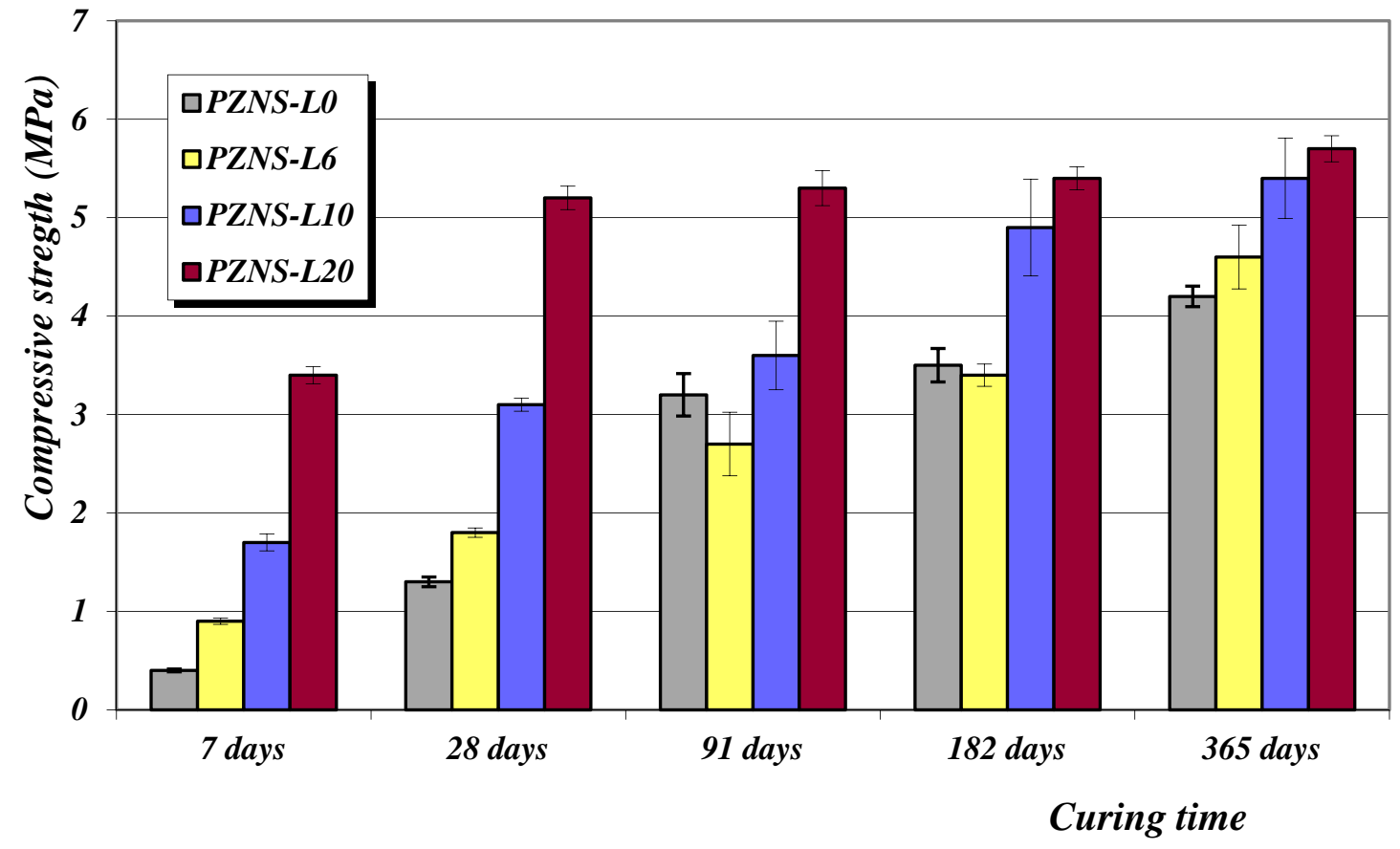

Figure 5. Compressive strength of the samples vs. curing times. 

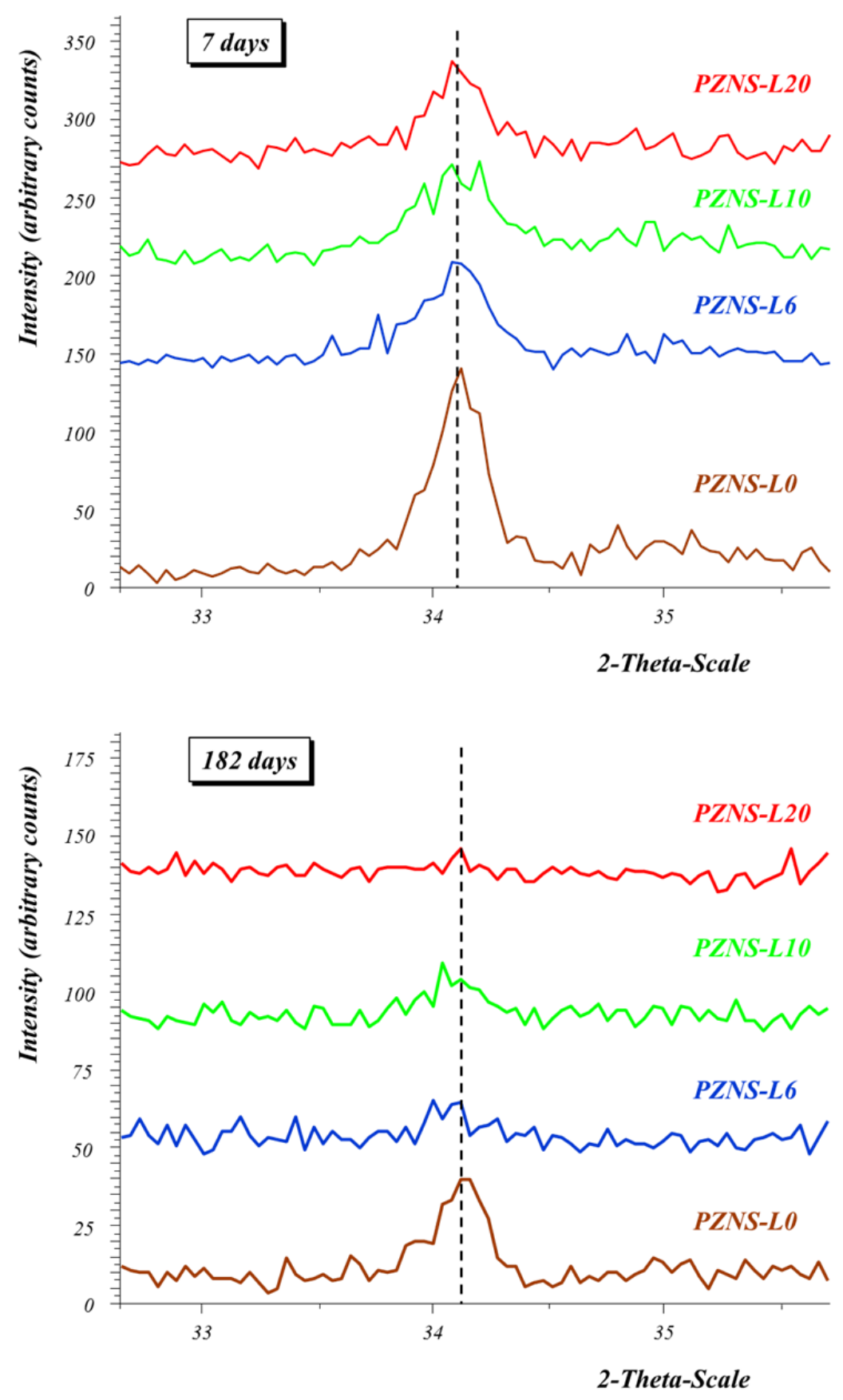

Figure 6. XRD evolution (main diffraction peak of the $\left.\mathrm{Ca}(\mathrm{OH})_{2}\right)$ after 7 and 182 curing days. 

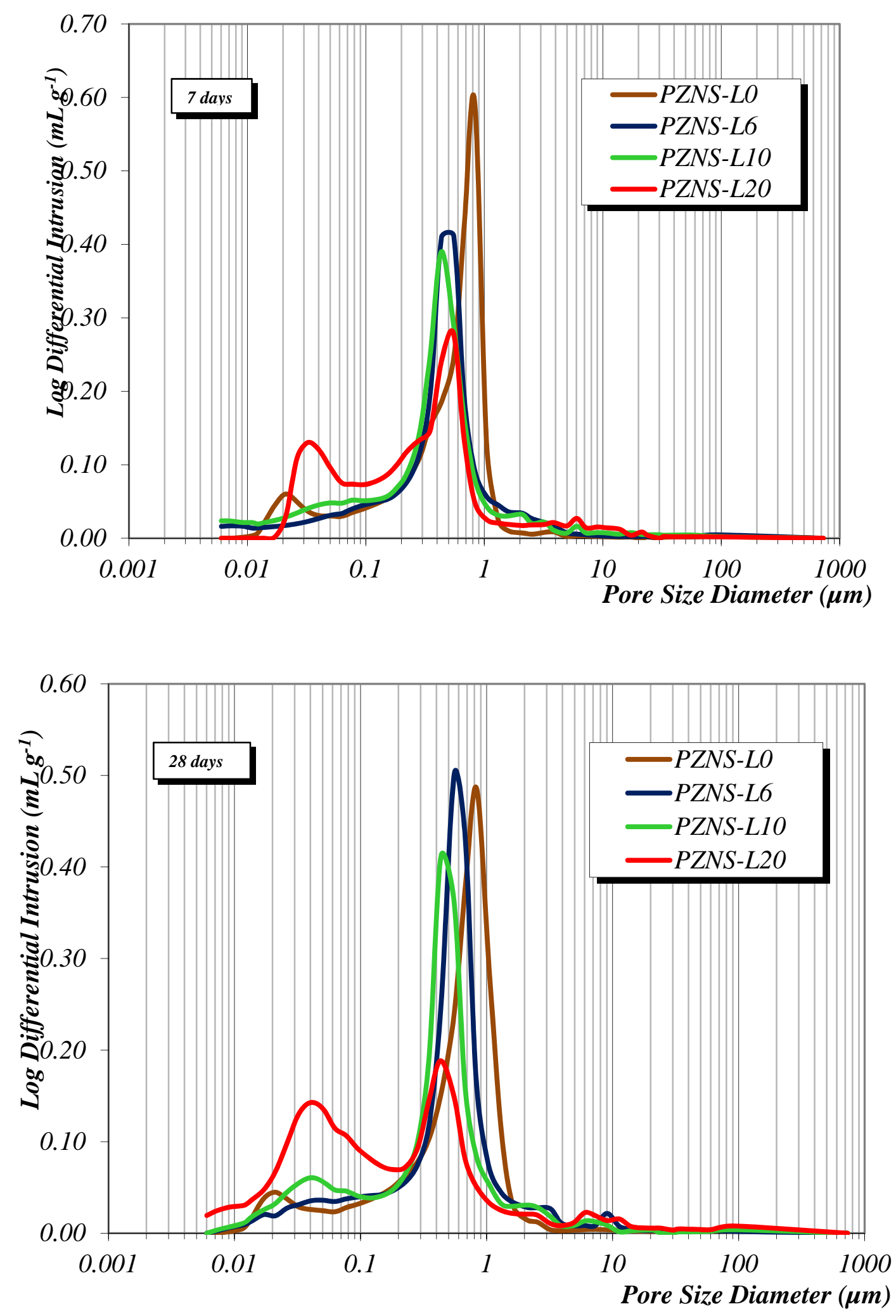

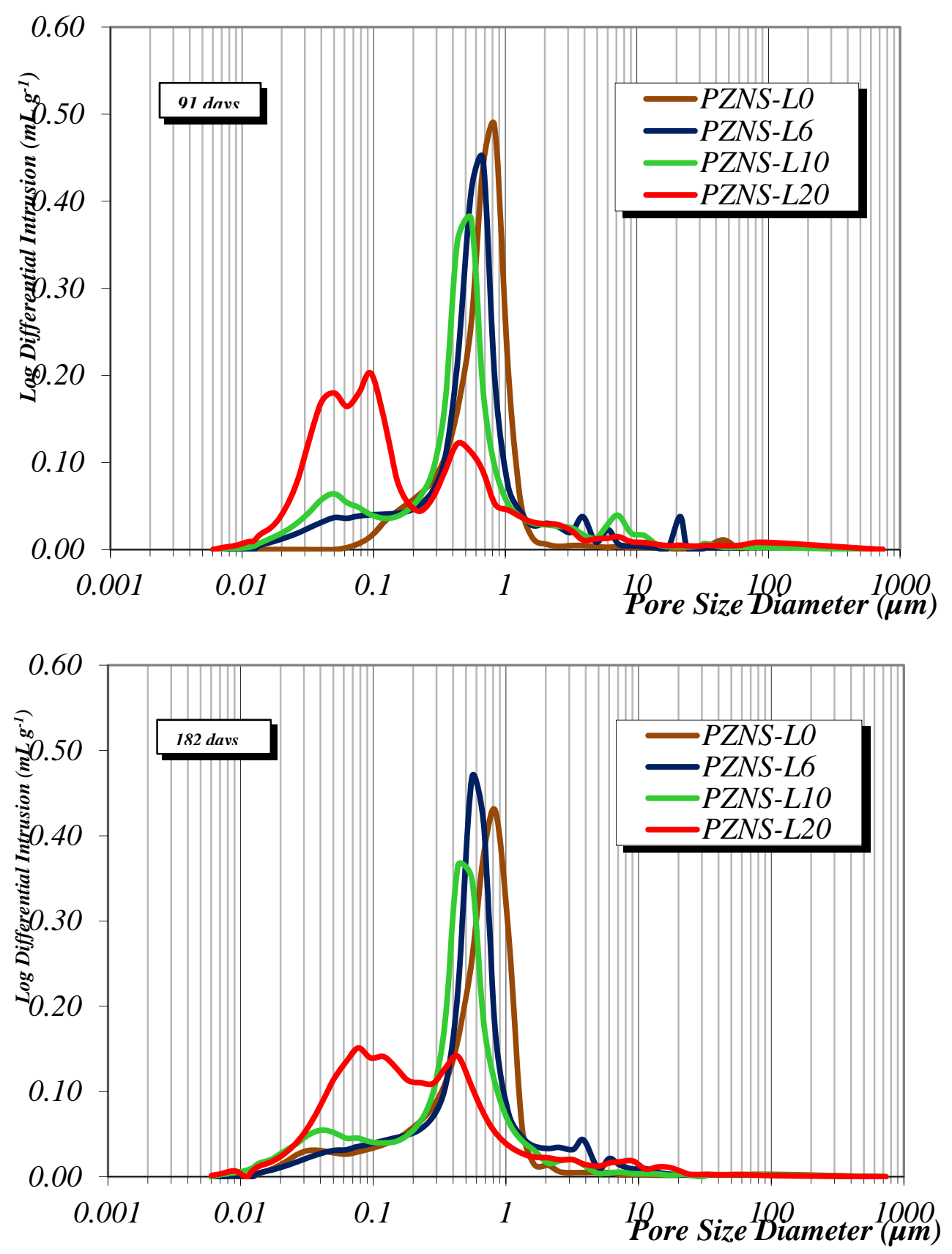


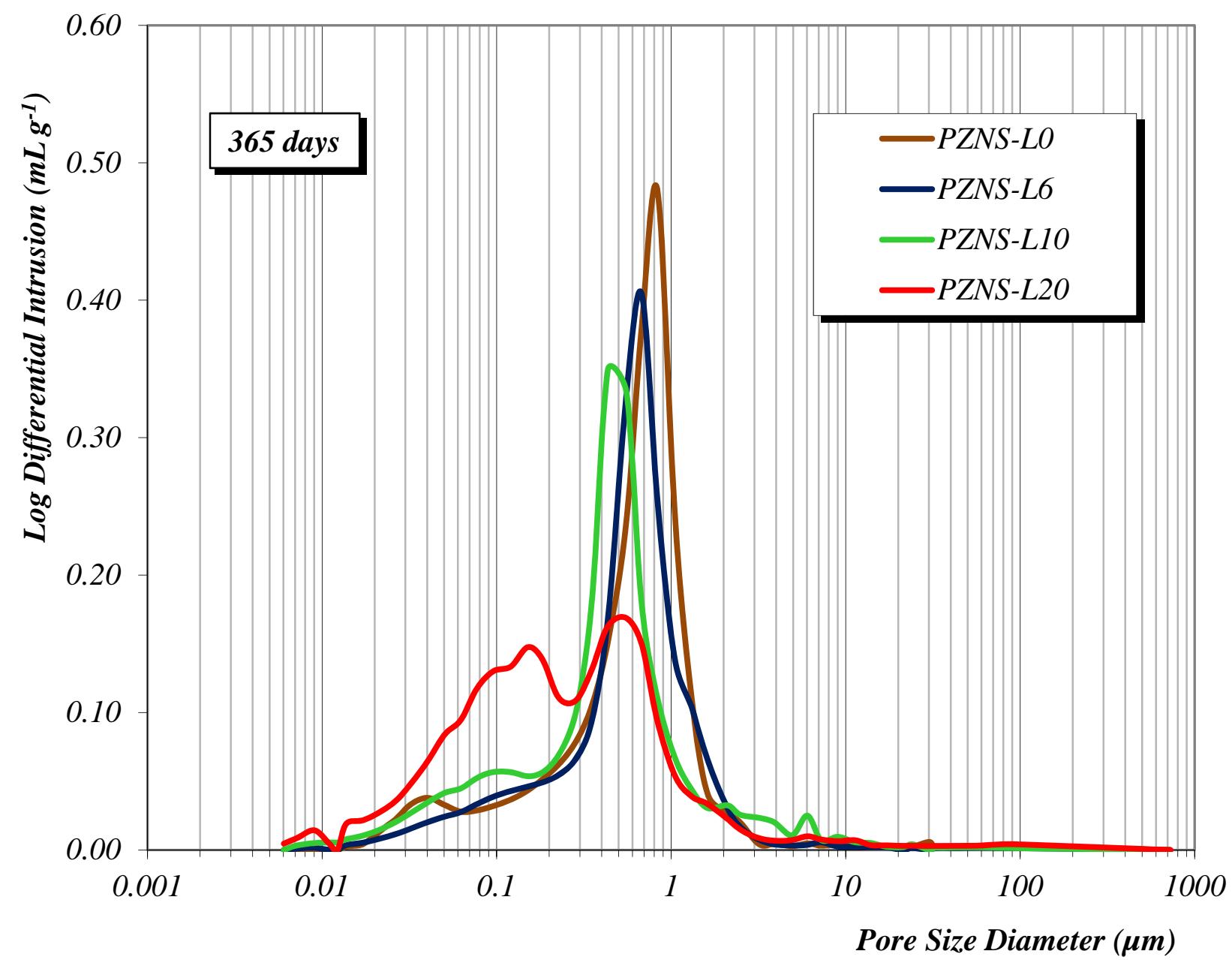

Figure 7. Pore size distributions of the samples after 7, 28, 91, 182 and 365 curing days. 

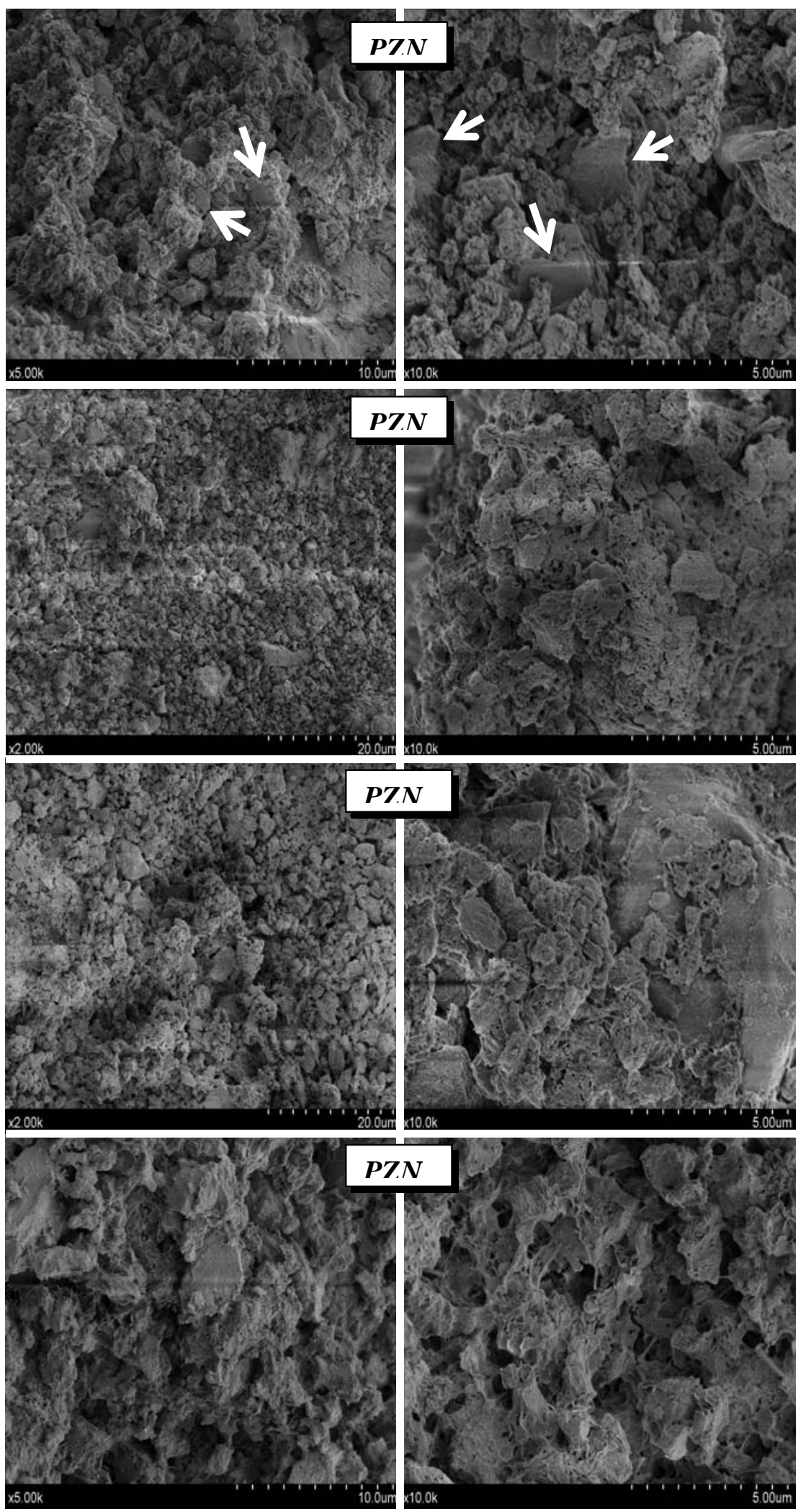

Figure 8. SEM micrographs of the samples after 91 curing days; left part shows micrographs at low magnification and right part at higher magnification. In the pictures of the plain lime mortar (sample PZNS-L0, in the top of the Figure, white arrows indicated the presence of hexagonal, plate-like crystals of portlandite. 

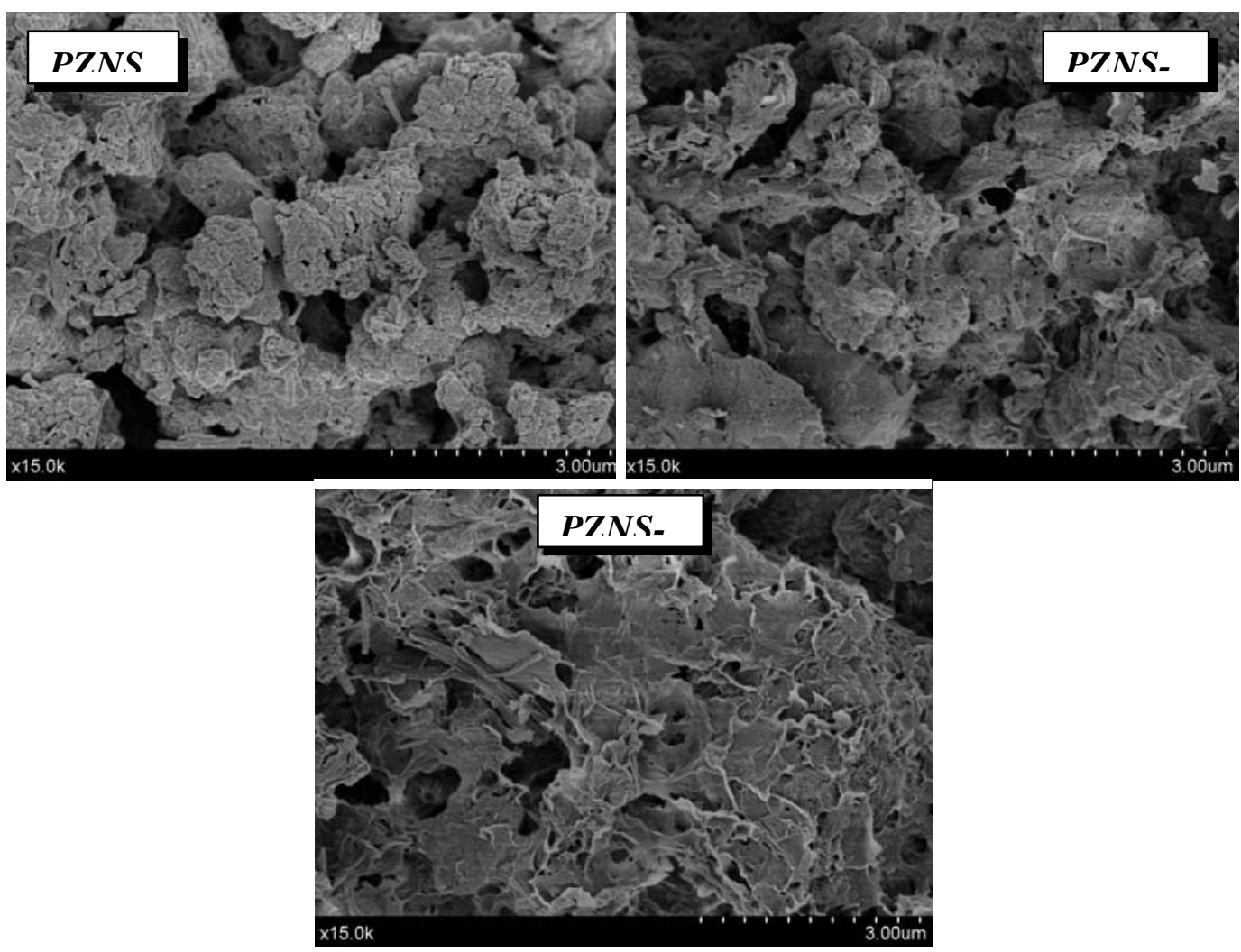

Figure 9. Micrographs obtained by SEM examination of samples after 182 curing days with increasing amounts of NS.

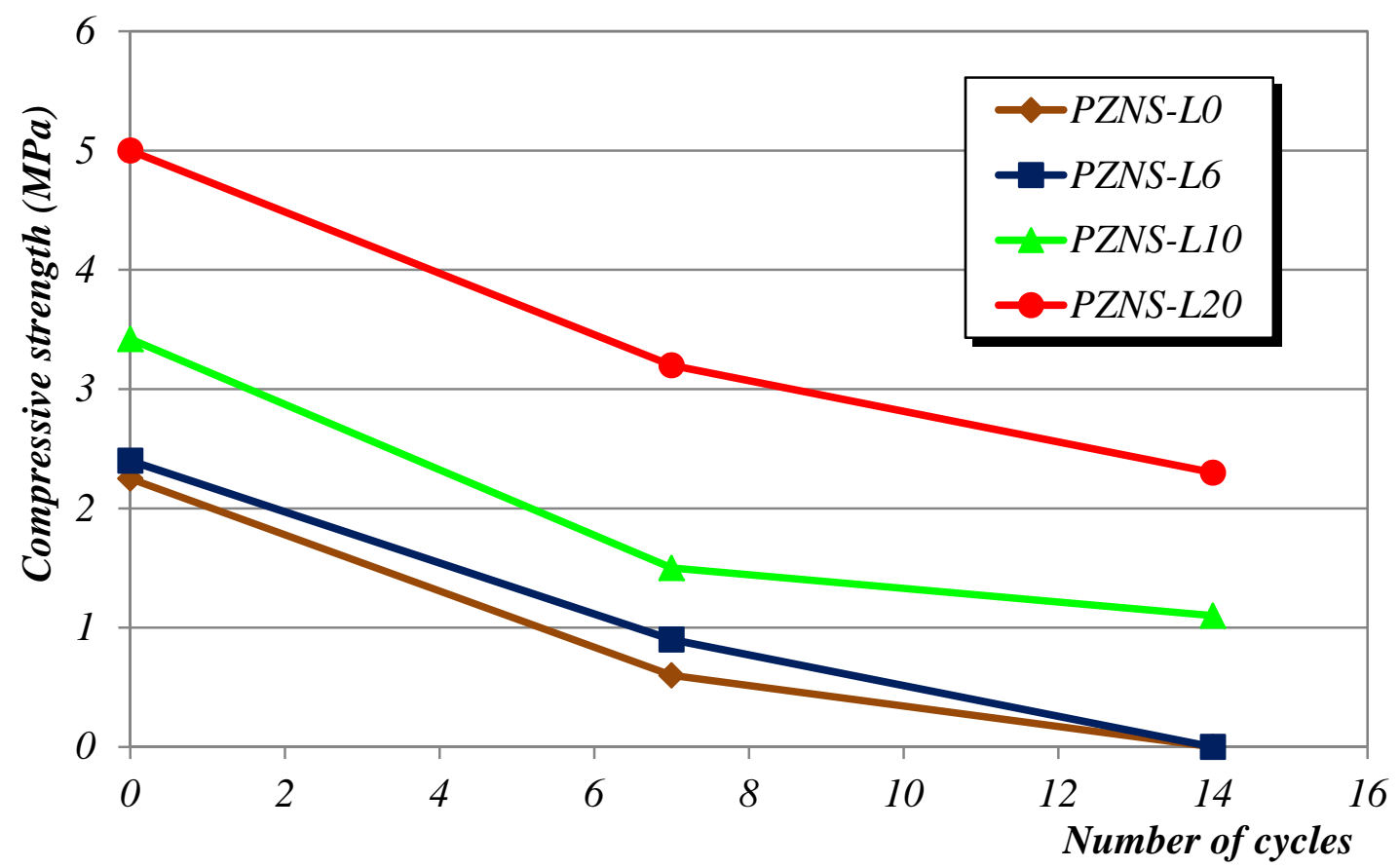

Figure 10. Effect of the climatic chamber exposure on the compressive strength 


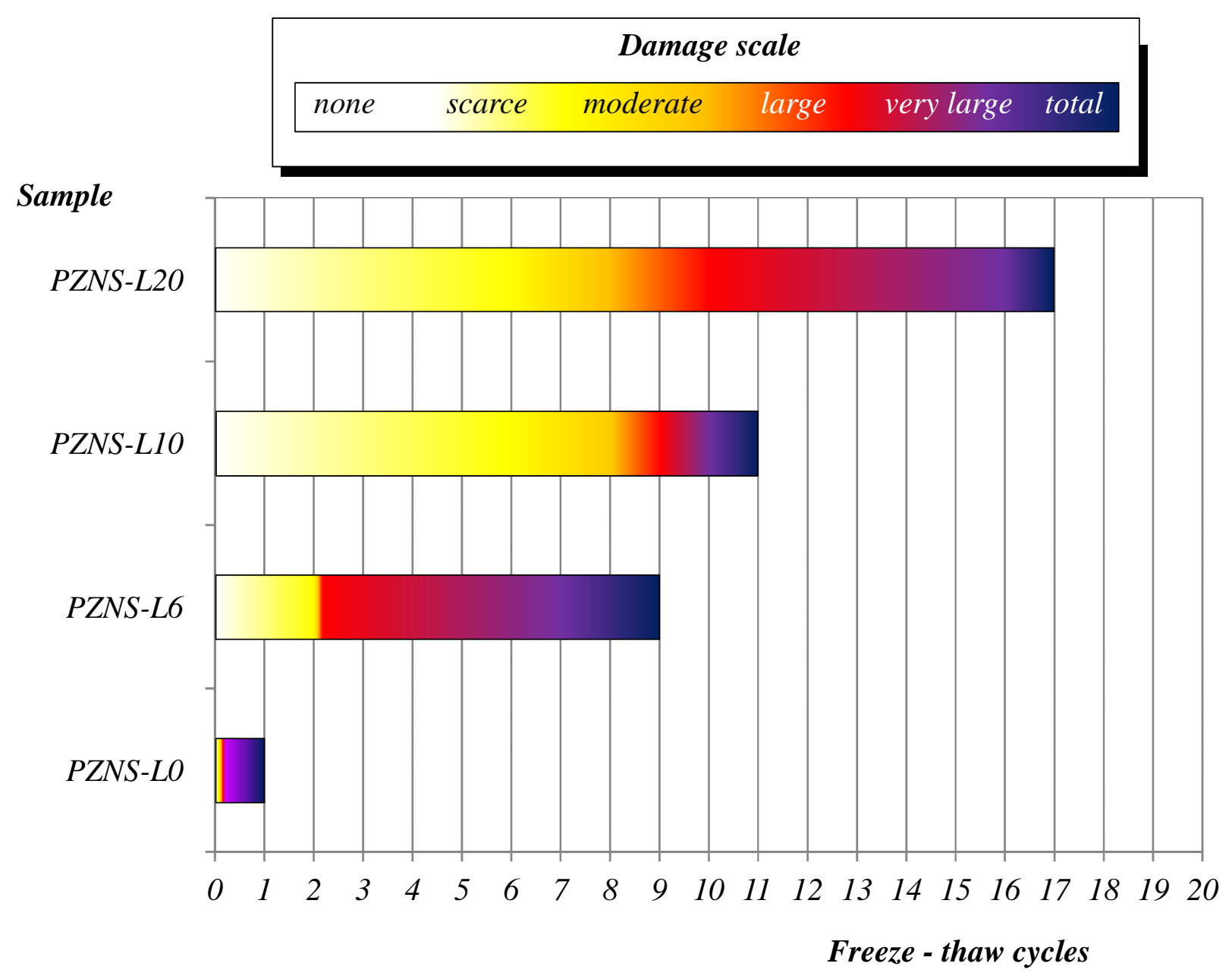

Figure 11. Alteration degrees (qualitative evaluation) of mortars after freeze-thaw cycles. 

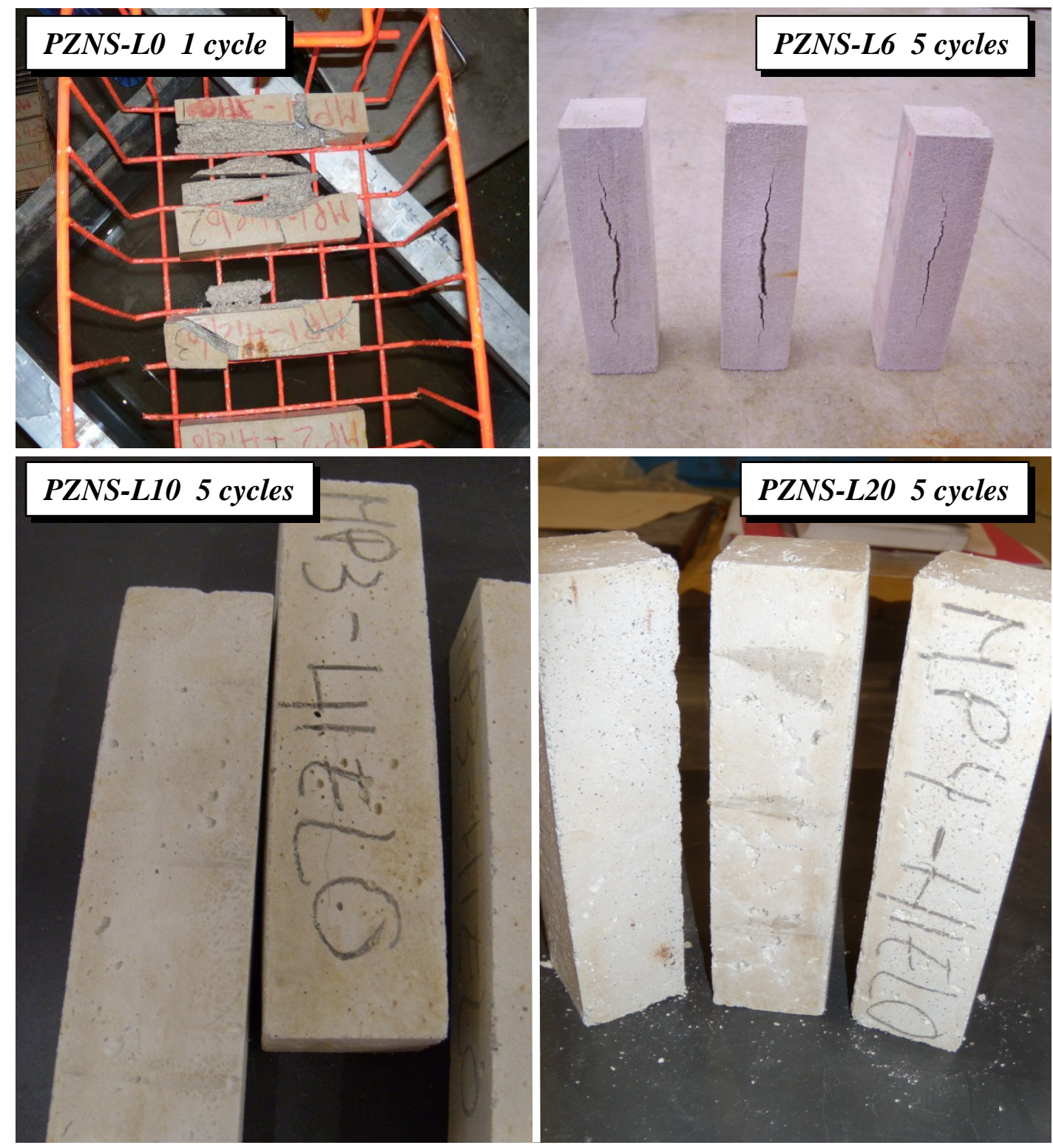

Figure 12. Samples' condition after freeze-thaw cycles: PZNS-L0, after just 1 cycle and PZNS-L6, PZNS-L10 and PZNS-L20 after 5 cycles. 

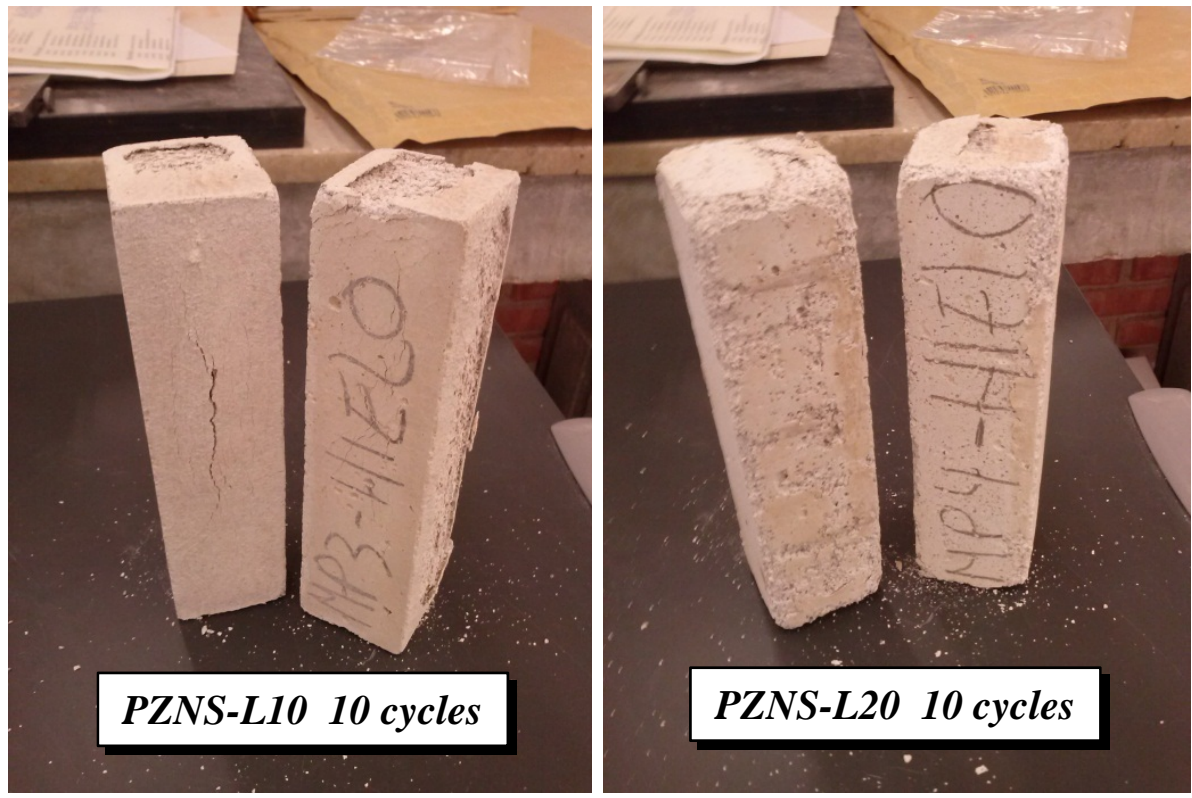

Figure 13. Samples after 10 freeze-thaw cycles (samples with $10 \mathrm{wt} \%$-left - and 20 wt.\% NS - right).

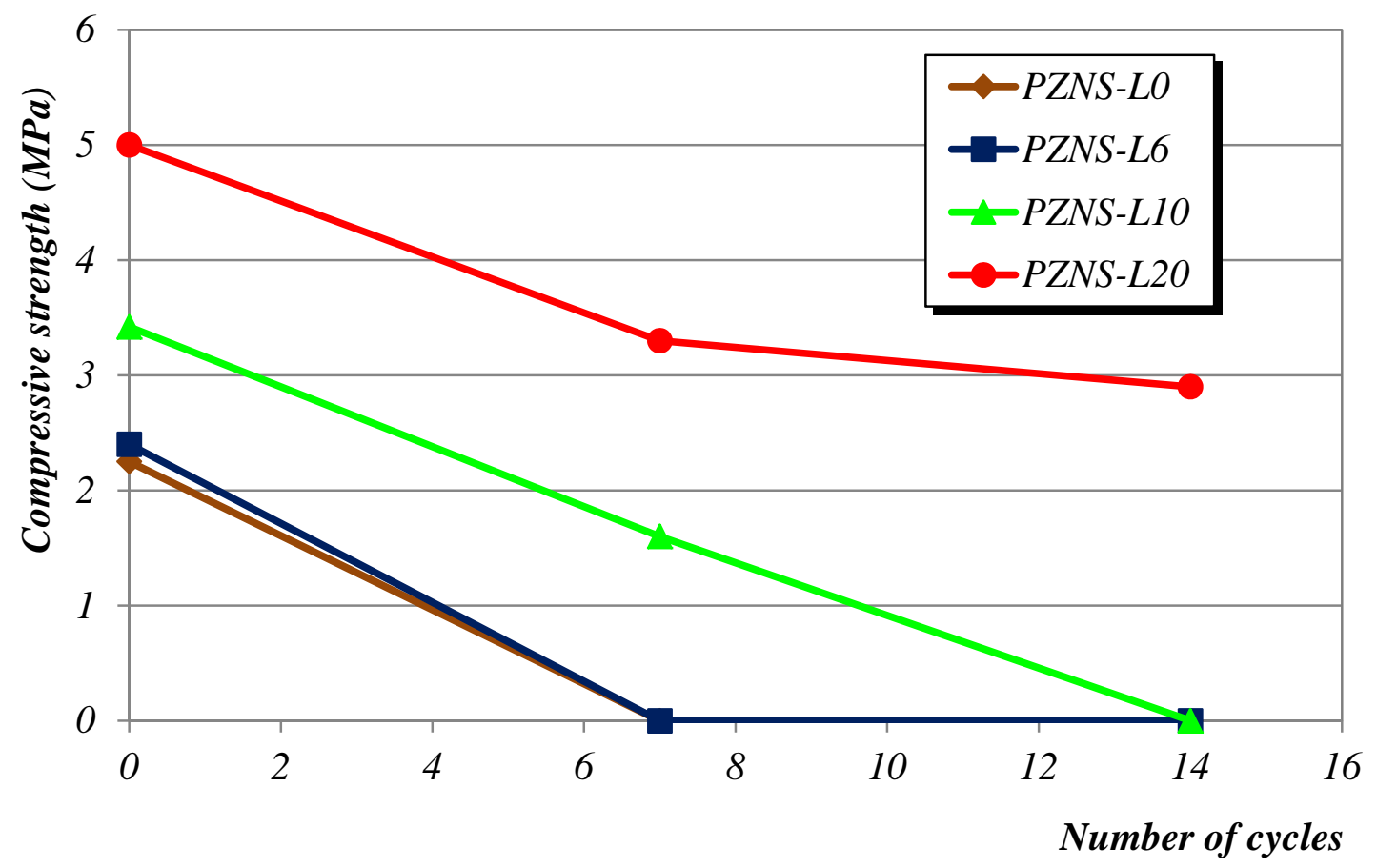

Figure 14. Influence of the freeze-thaw processes on the compressive strength of the samples. 


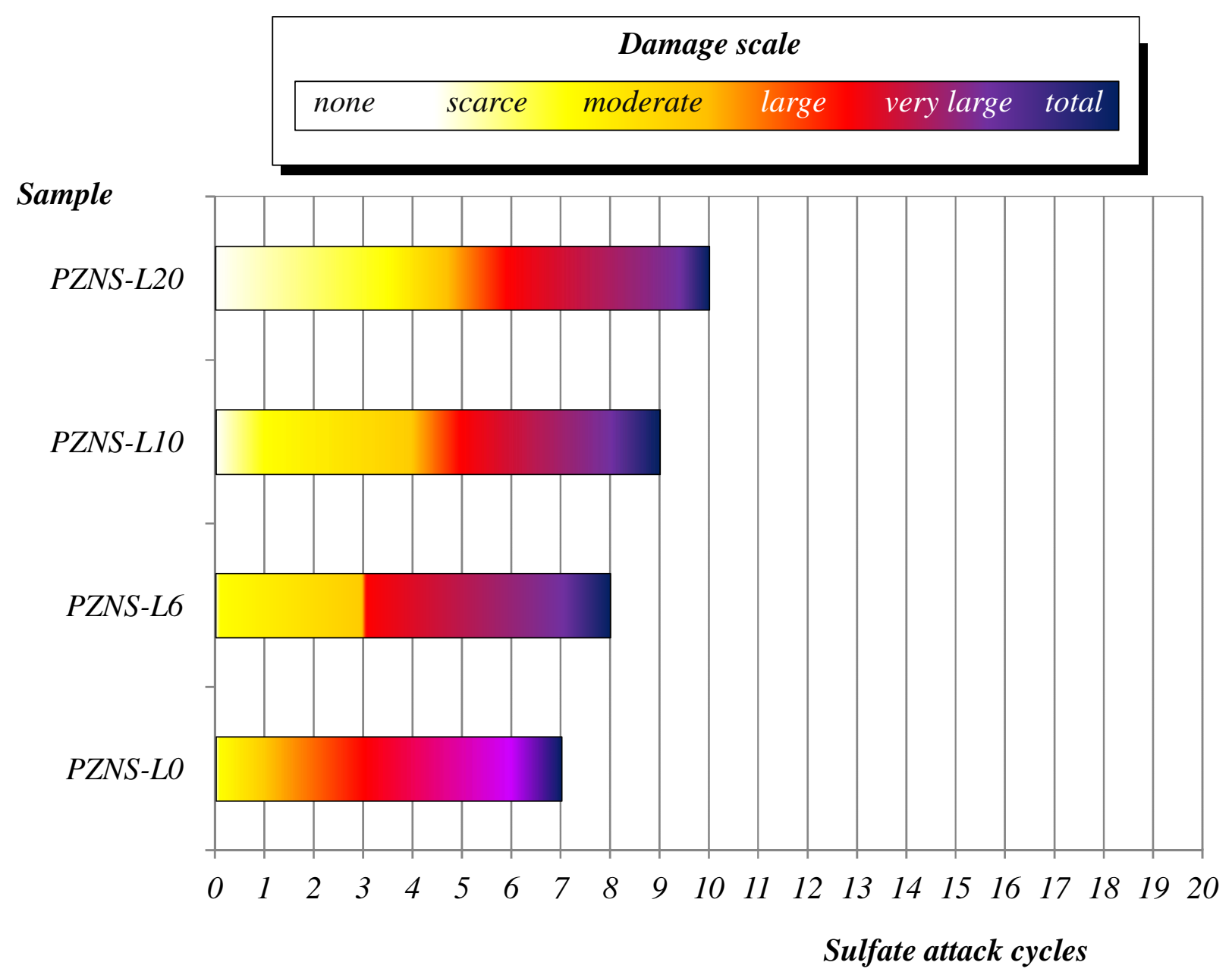

Figure 15. Qualitative alteration degrees (by visual appearance) of the samples after sulfate attack. 

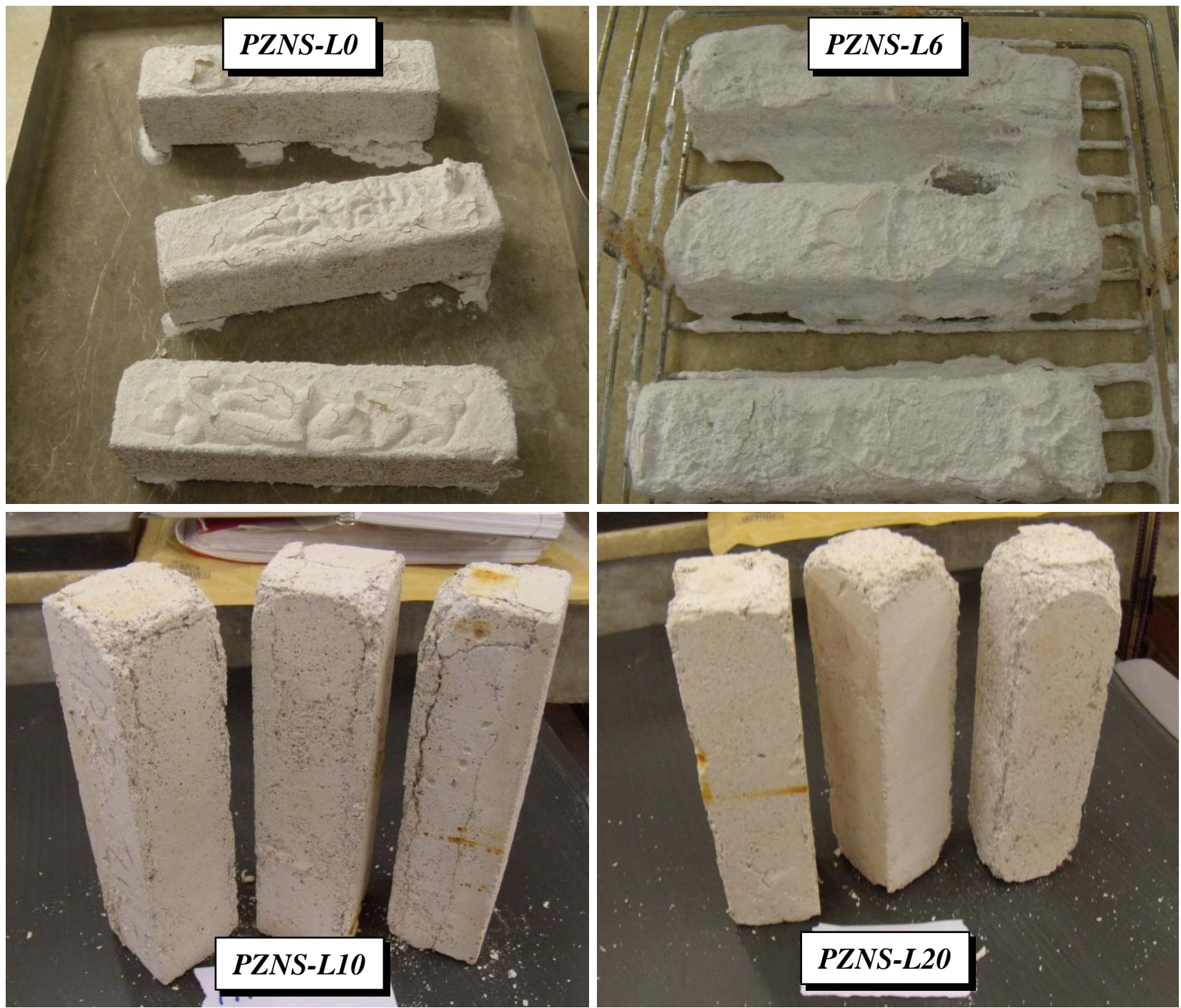

Figure 16. Damaging effect of the sulfate attack on the samples after 4 ageing cycles. 

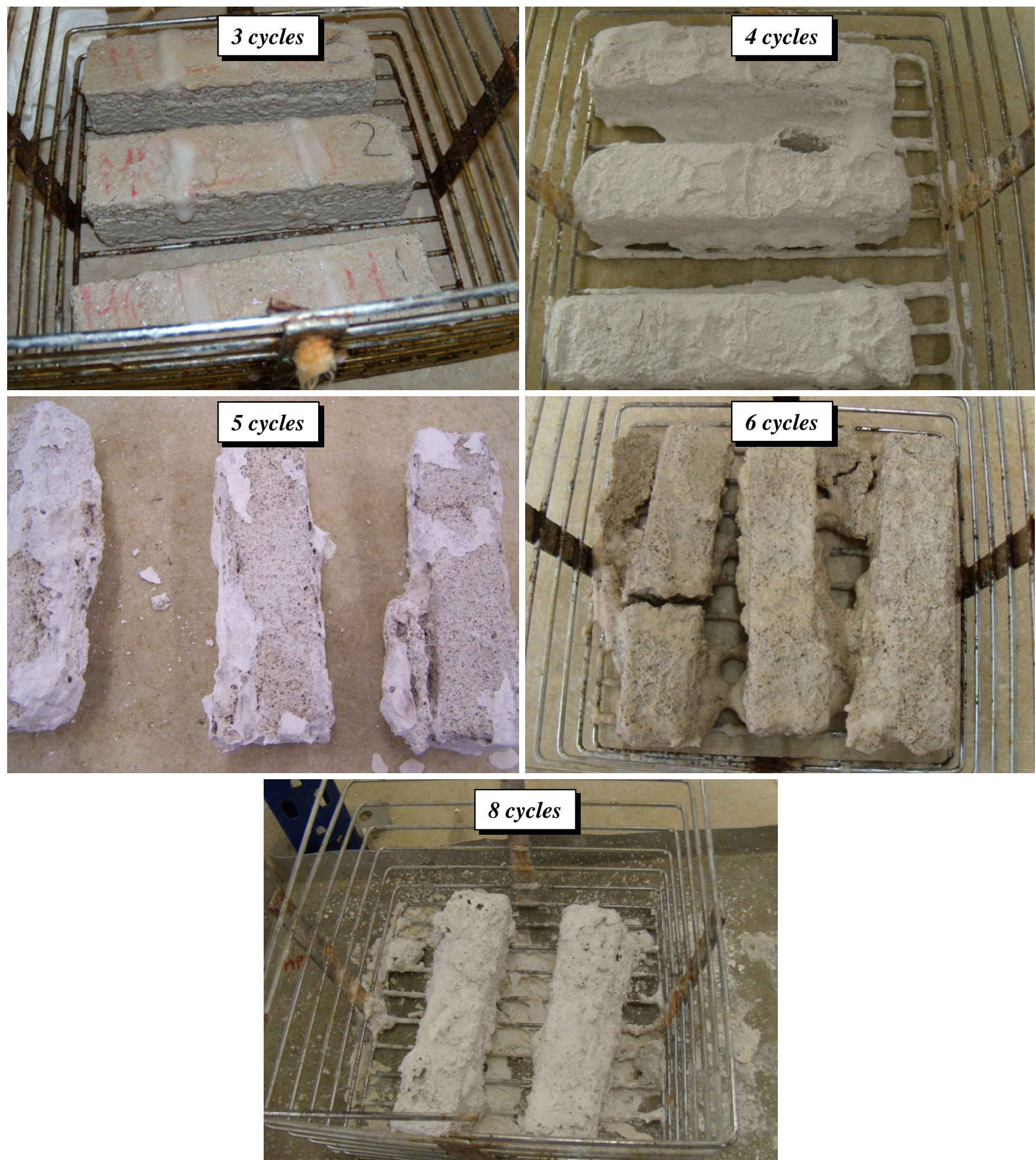

Figure 17. PZNS-L6 samples after 3, 4, 5, 6 and 8 cycles of exposure to sulfate attack, respectively. 
c: Calcite, $\mathrm{CaCO}_{3}, \mathrm{ICDD} 00-005-0586$

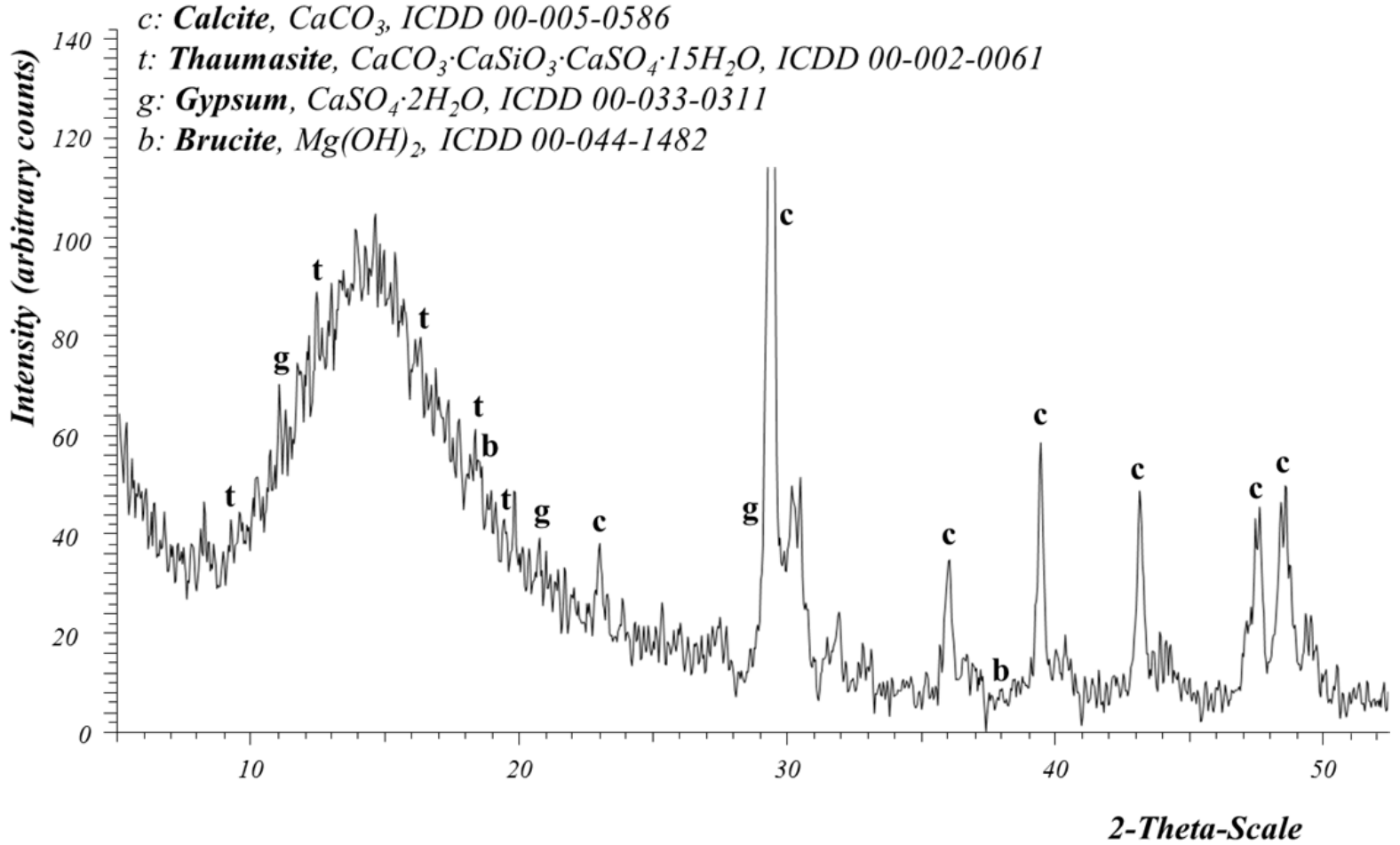

Figure 18. XRD analysis of the superficial degradation products of the PZNS-L6 sample after sulphate attack cycles.

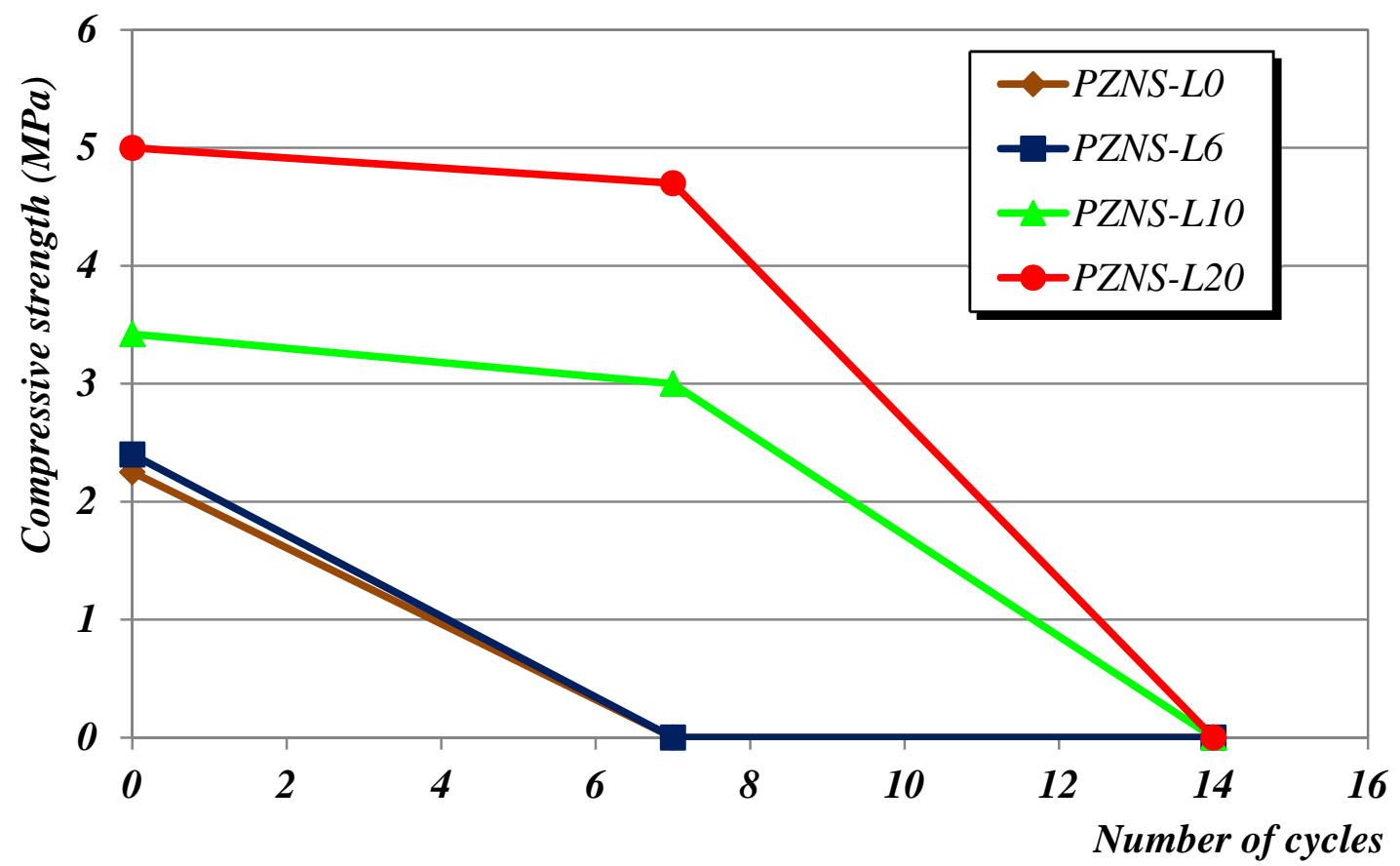

Figure 19. Variation of the compressive strength of the samples after several cycles of sulfate attack $\left(\mathrm{MgSO}_{4}\right)$. 